\title{
Intercomparison of Large-Eddy Simulations of the Antarctic Boundary Layer for Very Stable Stratification
}

\author{
Fleur Couvreux ${ }^{1}$ (D) - Eric Bazile ${ }^{1}$ - Quentin Rodier ${ }^{1}$ - Björn Maronga ${ }^{2,3}$. \\ Georgios Matheou ${ }^{4}$ Maria J. Chinita ${ }^{5,6}$. John Edwards ${ }^{7}$. Bart J. H. van Stratum ${ }^{8}$. \\ Chiel C. van Heerwaarden ${ }^{8}$. Jing Huang ${ }^{9}$ (D) Arnold F. Moene ${ }^{8}$. Anning Cheng ${ }^{10}$. \\ Vladimir Fuka ${ }^{12}$. Sukanta Basu ${ }^{11}$. Elie Bou-Zeid ${ }^{13}$. Guylaine Canut ${ }^{1}$. \\ Etienne Vignon ${ }^{14,15}$
}

Received: 29 October 2019 / Accepted: 7 June 2020 / Published online: 13 July 2020

(c) Springer Nature B.V. 2020

\begin{abstract}
In polar regions, where the boundary layer is often stably stratified, atmospheric models produce large biases depending on the boundary-layer parametrizations and the parametrization of the exchange of energy at the surface. This model intercomparison focuses on the very stable stratification encountered over the Antarctic Plateau in 2009. Here, we analyze results from 10 large-eddy-simulation (LES) codes for different spatial resolutions over 24 consecutive hours, and compare them with observations acquired at the Concordia Research Station during summer. This is a challenging exercise for such simulations since they need to reproduce both the 300-m-deep convective boundary layer and the very thin stable boundary layer characterized by a strong vertical temperature gradient $(10 \mathrm{~K}$ difference over the lowest $20 \mathrm{~m}$ ) when the sun is low over the horizon. A large variability in surface fluxes among the different models is highlighted. The LES models correctly reproduce the convective boundary layer in terms of mean profiles and turbulent characteristics but display more spread during stable conditions, which is largely reduced by increasing the horizontal and vertical resolutions in additional simulations focusing only on the stable period. This highlights the fact that very fine resolution is needed to represent such conditions. Complementary sensitivity studies are conducted regarding the roughness length, the subgrid-scale turbulence closure as well as the resolution and domain size. While we find little dependence on the surface-flux parametrization, the results indicate a pronounced sensitivity to both the roughness length and the turbulence closure.
\end{abstract}

Keywords Dome C A Antarctica $\cdot$ Large-eddy simulation $\cdot$ Parametrization $\cdot$ Stable boundary layer $\cdot$ Subgrid turbulence parametrization

Fleur Couvreux

fleur.couvreux@meteo.fr

Extended author information available on the last page of the article 


\section{Introduction}

A stable boundary layer (SBL) develops in the presence of a surface colder than the overlying air. Such conditions are encountered frequently in polar regions, over land during night-time and wintertime, and during the advection of warm air over a colder surface. The SBL can be classified according to the strength of the thermal inversion. Generally, the weaker SBL with continuous turbulence occurs when the wind speed is moderate to strong or in the presence of clouds limiting the surface radiative cooling. A model intercomparison for the weak SBL was conducted in the first intercomparison (GABLS1) of the GABLS (the GEWEX, Global Energy and Water Cycle Experiment, Atmospheric Boundary Layer Study) project (Beare et al. 2006). As shown in Beare et al. (2006), the turbulence under weak stratification, mainly mechanical turbulence forced by wind shear, is relatively well understood and described by similarity theory. This kind of turbulence is also correctly reproduced by high-resolution large-eddy simulations (LES; Beare et al. 2006; Huang and Bou-Zeid 2013; Matheou and Chung 2014). The strongly stratified SBL typically occurs in the presence of low wind speeds and clear skies, and is characterized by a strong temperature inversion. With an increase in stratification, turbulence can become intermittent or decoupled from the ground (Mahrt 1999; Sun et al. 2012; Mahrt 2014), making similarity theory inapplicable (Ha et al. 2007), and it is then a challenge to simulate the boundary layer even with a highresolution LES model. Van de Wiel et al. (2012) proposed a framework to predict the critical synoptic conditions for sustained turbulence and showed that, below a minimum wind-speed threshold, continuous turbulence is unlikely to occur. Vignon et al. (2017a) showed that the wind-speed threshold under which the very stable regime occurs lies between 5 and $6 \mathrm{~m} \mathrm{~s}^{-1}$ at Dome $\mathrm{C}$ (a meteorological and astronomical station in the high East Antarctic plateau), which exceeds the average wind speed observed at $10 \mathrm{~m}$ for the case considered here.

The accurate representation of the SBL is still a key issue for numerical weather prediction and climate models, particularly for very stable conditions. Numerical weather prediction models often report significant biases at night over land (Holtslag et al. 2013), with warm or cold biases depending on the excess of mixing or the strength of the decoupling with the surface. Indeed, Sandu et al. (2013) explain how enhanced turbulent diffusion is maintained in the European Centre for Medium-Range Weather Forecast model despite its detrimental impact on the SBL flow because it improves the simulation of the largescale flow and near-surface temperature. This study emphasises that enhanced diffusion is needed to compensate for errors caused by other poorly represented processes, encouraging more studies of processes in the SBL. Climate models also suffer from significant biases of temperature at low levels, with a strong climate signal in polar regions, where the results strongly depend on the type of boundary-layer parametrization (King et al. 2001). Several intercomparison activities endorsed by the GABLS project proposed different cases in which LES and single-column models (SCM) are intercompared in order to evaluate parametrization performance. The use of the LES approach has proven to be useful for the evaluation and development of parametrizations for clear and cloudy boundary layers (Randall et al. 2003; Hourdin et al. 2013). One aim of GABLS investigations has been also to evaluate the spread among different LES models in order to examine how reliable are these high-resolution simulations, and to what degree they can be used as a guidance for the parametrization of the SBL. Three different GABLS intercomparisons have already been carried out, focusing on progressively more realistic cases. 
The first intercomparison (GABLS1) uses an idealized set-up over an icy surface with the development of a shear-driven SBL (Beare et al. 2006) based loosely on observations from the Arctic corresponding to weakly stable conditions. A prescribed uniform geostrophic wind speed of $8 \mathrm{~m} \mathrm{~s}^{-1}$ and a constant surface cooling of $0.25 \mathrm{~K} \mathrm{~h}^{-1}$ were applied and neither radiation nor surface interaction was taken into account. Beare et al. (2006) found relatively good agreement among the different LES models and Cuxart et al. (2006) further used the LES results as a reference for a SCM intercomparison. Cuxart et al. (2006) also showed that the SCM approach generally overestimates mixing, except when a prognostic turbulence kinetic energy (TKE) parametrization is employed.

The second intercomparison (GABLS2) is based on observations from the Cooperative Atmospheric Surface Exchange Study (CASES-99) field campaign and aimed at representing a complete diurnal cycle with the SCM approach (Svensson et al. 2011). For this case, simulations were performed with a prescribed surface temperature inhibiting a possible surface-boundary layer interaction. While the intercomparison focused on the evaluation of the turbulence parametrizations, most of the spread between model results was attributed to differences in interactions between surface fluxes and stability.

The third intercomparison (GABLS3) is more closely based on observations from the Cabauw tower, with special emphasis placed on the analysis of the coupling with the surface and the radiation (Bosveld et al. 2014a, b). The observed near-surface potential temperature and moisture were prescribed to enable a focus on the role of numerical schemes and subgrid-scale (SGS) turbulence parametrizations on the boundary-layer profiles. The different LES models were found to be in very good agreement (Holtslag et al. 2013).

However, since the prior three cases did not tackle the strong SBL, this is the main objective of the GABLS4 intercomparison (Bazile et al. 2014), which is based on the observations from a meteorological tower at Dome $\mathrm{C}$ on the Antarctic Plateau (Genthon et al. 2013) on 11 December 2009. This site has been chosen because of, (i) the relatively large dataset acquired in the framework of the Concordiasi field campaign (Rabier et al. 2010); (ii) the flatness and homogeneity of the ground: topography and surface heterogeneities are significant factors of turbulence in stable conditions as even a gradual slope can produce drainage flows (Mahrt and Larsen 1990); (iii) the dryness of the air. Indeed, the occurrence of a clear and clean atmosphere containing very little water vapour induces strong radiative cooling at the surface reaching $>2 \mathrm{~K} \mathrm{~h}^{-1}$ when the sun is very low above the horizon.

On 11 December 2009, the boundary layer was convective when the sun was high above the horizon, with the layer reaching a height of a few hundred metres. This is a frequent feature over Dome C, as highlighted previously by King et al. (2006); Ricaud et al. (2012); Genthon et al. (2013); Casasanta et al. (2014), by revealing frequent convective-boundarylayer heights of $250 \mathrm{~m}$ to $350 \mathrm{~m}$ in summer. On that day and also consistent with the climatology, when the sun was low above the horizon, strong vertical gradients of temperature were measured close to the surface at Dome $\mathrm{C}$ with values reaching $>0.7 \mathrm{~K} \mathrm{~m}^{-1}$. The net radiation varies throughout the $24 \mathrm{~h}$ from $49 \mathrm{~W} \mathrm{~m}^{-2}$ at $0400 \mathrm{UTC}$ (local time $=\mathrm{UTC}+8 \mathrm{~h}$ ) and $-44 \mathrm{~W} \mathrm{~m}^{-2}$ at $1600 \mathrm{UTC}$, which are typical values for surfaces covered by snow during the summer conditions over Antarctica (King et al. 2006).

Three different stages were proposed for the GABLS4 intercomparison (Bazile et al. 2014). The first is dedicated to an SCM intercomparison with an interactive snow surface parametrization, the second prescribes the observed surface temperature (suppressing feedback from the surface), and the third is an idealized case that simplifies the large-scale forcing and initial conditions. Here, we focus on stage 3, which is the most idealized setup, including prescribed surface temperature, no radiation, no specific humidity, and a 
constant large-scale forcing with time. This case is challenging for LES models as it incorporates the full diurnal cycle with both a relatively deep convective boundary layer at midday and an extremely thin boundary layer when the sun is very low over the horizon. Our objective is to evaluate the skill of various LES models at such stability. Indeed, at such strong stability, we test the limit of the validity of the LES technique that has been shown to represent convective boundary layers satisfactorily and the weak SBL in the previous GABLS exercises. We expect deficiencies of the LES models in reproducing the strong SBL because of, (i) a possibly problematic estimation of the dissipation associated with the existence of non-isotropic subgrid turbulence (only a few subgrid-turbulence parametrizations do not assume isotropy), or a misrepresentation of the buoyant destruction by the subgrid-turbulence parametrization (Bou-Zeid et al. 2010); (ii) the importance of radiative flux divergence (as in many LES studies, the radiative flux divergence is neglected); (iii) the weak surface turbulent fluxes; (iv) the fine grid resolution required to resolve most of the turbulence. We also investigate the necessary resolution for resolving the main processes in such stable cases and how the results depend on the SGS turbulence and surface parametrizations. Several studies have shown that it is difficult to obtain convergence of the results for a given model, with results even at high resolution still not converging (Huang and Bou-Zeid 2013; Van Stratum and Stevens 2015; Sullivan et al. 2016 and Maronga et al. 2020a, b, among others).

Very few studies have focused on the representation of the strongly stratified SBL in LES models. Huang and Bou-Zeid (2013) simulated a suite of GABLS1-based test cases by increasing the surface cooling up to $-2.5 \mathrm{~K} \mathrm{~h}^{-1}$ and obtained a largely expanded stability range where the gradient Richardson number reached values of around unity. They systematically investigated the effects of stability on the bulk dynamics, turbulent structure, and budget of TKE, as well as the applicability of local similarity theory in the SBL, and found that, (i) the vertical extent of turbulent structures is reduced with increasing stability; (ii) buoyant destruction of TKE becomes more important than viscous dissipation under the strongest stabilities; and (iii) the $z$-less range of scaling in the SBL applies at lower heights than previously anticipated. Walesby and Beare (2016) proposed a case derived from observations from the Halley research station on the Brunt iceshelf for both the LES and SCM approaches. They used the LES result as a reference to show that the choice of stability functions is critical for the SCM behaviour. Following Huang and Bou-Zeid (2013), Sullivan et al. (2016) modified the GABLS1 set-up by imposing stronger surface cooling up to $-1 \mathrm{~K} \mathrm{~h}^{-1}$ in order to obtain very stable conditions and constructed highly resolved $(\Delta x=\Delta y=\Delta z=0.39 \mathrm{~m})$ simulations that ran for nine physical hours. They noted a decrease of the SBL height with increasing resolution, revealed the existence of temperature microfronts in the simulations, and also found that grid convergence was not reached in their simulations. Recently, Maronga et al. (2020) investigated whether the surface boundary conditions (i.e. Monin-Obukhov similarity theory, MOST) are responsible for the lack of grid convergence observed in stable conditions. While grid convergence was significantly improved for the surface fluxes of heat and momentum, they found that the non-convergence of the mean profiles could not be ascribed to the boundary conditions. Van der Linden et al. (2019) simulated accurately both the winter weak and strong SBL observed at Dome $\mathrm{C}$ with a very fine ( $\mathrm{cm}$-scale) LES model, showing that a thermal equilibrium can be reached between subsidence (heating) and turbulence (cooling).

Our main objective is to present the results of the first LES intercomparison in very stable conditions. Below, Sect. 2 details the methodology for the intercomparison, focusing on the case and model description but also giving information on the diagnostics and the sensitivity tests. Section 3 presents the main results with a distinction between the 
(a)

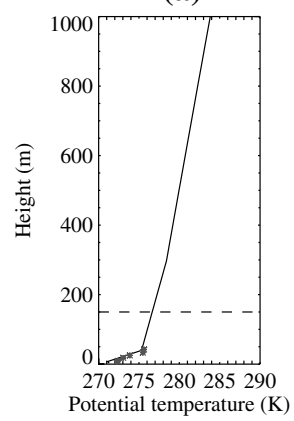

(b)

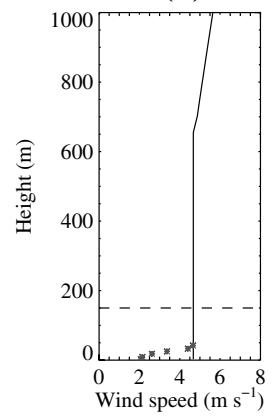

(c)

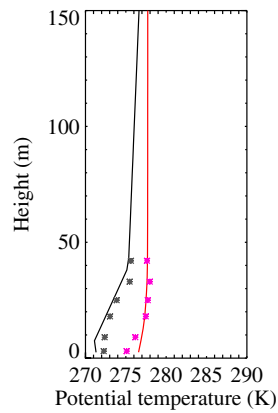

(d)

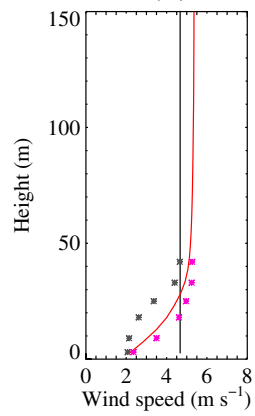

(e)

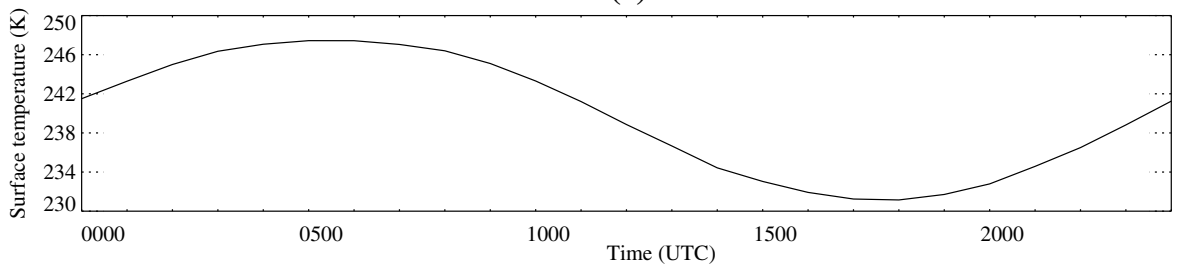

Fig. 1 Vertical profiles of initial conditions: a, c potential temperature, $\mathbf{b}, \mathbf{d}$ wind speed at 0000 UTC for the 24-h (black) and10-h (red) runs. Panels c and d show a magnification of the lowest $150 \mathrm{~m}$; this upper bound is indicated by a dashed line in panels a and c. e Time series of the prescribed surface temperature. Observations from Dome $\mathrm{C}$ are indicated by markers

representation of the convective and stable behaviour of the boundary layer. Section 4 presents the different sensitivity tests and the paper closes with conclusions and recommendations for future LES intercomparisons in very stable conditions. A forthcoming companion paper presents the results of the SCM intercomparison.

\section{Methodology}

\subsection{Case Description}

As documented by Bazile et al. (2014), the present case is based on observations from Dome C (123.30E, 75.10S, $3223 \mathrm{~m}$ above sea level) on the Antarctic Plateau (Genthon et al. 2013). Recall that this case occurs in summer in Antarctica, so there is daylight throughout $24 \mathrm{~h}$ although the net radiative energy at the surface is positive (negative) when the sun is high (low) above the horizon. Here, the simplest set-up is used in order to allow contributions to this intercomparison from many modelling groups. In particular, the case neglects radiation and land-surface interactions. Furthermore, the large-scale forcing includes only the geostrophic wind speed, which is assumed constant in time and with height. Temperature advection and subsidence are not included in the case set-up. The initial profiles of potential temperature, and the zonal and meridional velocity components are derived from the soundings launched at 0000 UTC (0800 local time; see Fig. 1 and Table 5). The initial sounding consists of a SBL with a relatively large temperature gradient up to $45 \mathrm{~m}$ below a less stable layer. The wind speed is almost constant with height (except in the lowest part 
of the boundary layer) at around $4 \mathrm{~m} \mathrm{~s}^{-1}$. The case is considered dry (note that the water vapour mixing ratio is low at Dome $C$ with typical values of $0.3 \mathrm{~g} \mathrm{~kg}^{-1}$; see Genthon et al. 2017). A spatially uniform time-dependent temperature derived from observations is prescribed to provide the surface boundary condition (Table 5). As shown in Fig. 1e, there is a warming of the surface for the first $5 \mathrm{~h}$ of the simulation followed by a cooling. The largest cooling occurs in the period 1100-1600 UTC with values of approximately $2 \mathrm{~K} \mathrm{~h}^{-1}$, which is a significantly larger cooling than the $0.25 \mathrm{~K} \mathrm{~h}^{-1}$ used in GABLS1 intercomparison (Beare et al. 2006) or the range of cooling used in Sullivan et al. (2016), which increases from 0.25 to $1 \mathrm{~K} \mathrm{~h}^{-1}$. The thermal and momentum roughness lengths are also prescribed as $z_{0 m}=10^{-2} \mathrm{~m}$ for momentum and $z_{0 h}=10^{-3} \mathrm{~m}$ (experiment 1 ). To match better with the observations (Vignon et al. 2017b), additional simulations are performed with momentum and thermal roughness lengths of $10^{-3} \mathrm{~m}$ and $10^{-4} \mathrm{~m}$, respectively. The default case is named experiment 1 while the case with modified roughness lengths is called experiment 2. The sensitivity of the LES results to the roughness lengths is discussed in Sect. 4.

Simulations of the convective part of the diurnal cycle require large computational domains because of the relatively large boundary-layer height compared with that encountered in stable conditions. Thus, the grid resolution is constrained by the height of the convective layer and the SBL is only captured by the lowermost few model layers. In order to focus on the stable conditions and optimize the grid resolution, experiment 3 was carried out in which simulations start at 1000 UTC (instead of 0000 UTC) and the ensemble mean profiles of experiment 2 are used as the initial conditions (Fig. 1a-d and Table 5 for numerical values). The same large-scale forcing and surface boundary conditions of experiments 1 and 2 are used, as are the roughness lengths used in experiment 2. The initial profile of potential temperature at 1000 UTC is close to neutrality.

Although the set-up is idealized from the real conditions that occurred on 11 December 2009, we include the observations in the following figures where possible to illustrate the expected behaviour. In particular, observations from a 45-m meteorological tower with six levels $(3 \mathrm{~m}, 9 \mathrm{~m}, 18 \mathrm{~m}, 25 \mathrm{~m}, 33 \mathrm{~m}, 42 \mathrm{~m})$ of wind speed and temperature measurements, as well as four levels $(7 \mathrm{~m}, 23 \mathrm{~m}, 30 \mathrm{~m}, 38 \mathrm{~m})$ of turbulent-flux measurements are shown. The turbulent quantities are measured by sonic thermo-anemometers that sample at $10 \mathrm{~Hz}$. Because of the very cold conditions encountered, the instruments record data for $8 \mathrm{~min}$, which is followed by period of heating for $12 \mathrm{~min}$. Turbulent quantities were computed over a 60 -min period corresponding to $24 \mathrm{~min}(3 \times 8 \mathrm{~min})$ of effective measurements. We refer to Vignon et al. (2017a) for more information on the complete derivation of these turbulent quantities and to Genthon et al. (2013) for details of the temperature and wind-speed measurements.

The boundary-layer height in convective conditions is defined as the level at which the vertical potential temperature flux is minimum and follows the definition used in Beare et al. (2006) for stable conditions, where $z=h$ is the level (divided by 0.95) where the mean stress reaches $5 \%$ of its surface value. The Obukhov length $L$ is also computed as

$$
L=\frac{-\left({\overline{u^{\prime} w^{\prime}}}^{2}+{\overline{v^{\prime} w^{\prime}}}^{2}\right)^{(3 / 4)}}{\kappa \frac{g}{\bar{\theta}} \overline{\theta^{\prime} w^{\prime}}}
$$

where $U, V$ are the zonal and meridional velocity components, $\theta$ is the potential temperature, $\overline{u^{\prime} w^{\prime}}, \overline{v^{\prime} w^{\prime}}, \overline{\theta^{\prime} w^{\prime}}$ are the momentum and temperature turbulent fluxes, $k$ is the von Kármán constant, and $g$ is the acceleration due to gravity. 
The effective diffusivities of momentum $K_{m}^{\text {eff }}$ and heat $K_{h}^{\text {eff }}$ are calculated from the total momentum and heat fluxes and the mean wind-speed and potential temperature profiles following Beare et al. (2006) as

$$
K_{m}^{\mathrm{eff}}=\frac{\left({\overline{u^{\prime} w^{\prime}}}^{2}+{\overline{v^{\prime} w^{\prime}}}^{2}\right)^{1 / 2}}{\left(\left(\frac{\partial U}{\partial z}\right)^{2}+\left(\frac{\partial V}{\partial z}\right)^{2}\right)^{1 / 2}}
$$

and

$$
K_{h}^{\mathrm{eff}}=\frac{\overline{\theta^{\prime} w^{\prime}}}{\frac{\partial \theta}{\partial z}}
$$

\subsection{Models}

In total, 10 different LES models contributed to this exercise (see Tables 1 and 2). All the models use their own model-specific SGS parametrization and discretization in space and time (see Table 1). Most of the SGS parametrizations are based either on a prognostic equation for the TKE with a Deardorff (1974) length scale, or a Smagorinsky (1963) approach with or without a dynamic component. In particular, the $\mathrm{CSIRO}^{1}$ and MATLES${ }^{2}$ models use advanced scale-dependent SGS models to calculate the SGS eddy viscosity (Bou-Zeid et al. 2005; Basu and Porte-Agel 2006), which have been shown to simulate the SBL reliably even under strong stability (Huang and Bou-Zeid 2013). The University of Connecticut LES model (UConn) uses the buoyancy-adjusted stretched-vortex model (Chung and Matheou 2014), and the sensitivity to the SGS turbulence parametrization for this model is presented in Sect. 4. All models use a MOST-based formulation (see Cuxart et al. 2006), with an integral formulation to calculate the surface turbulent fluxes following

$$
\frac{\partial U}{\partial z}=\frac{u_{*}}{\kappa z} f_{m}\left(\frac{z}{L}\right)
$$

and

$$
\frac{\partial \theta}{\partial z}=\frac{\theta_{*}}{\kappa z} f_{h}\left(\frac{z}{L}\right)
$$

with $U$ being the wind speed, $L$ the Obukhov length, $u_{*}$ the friction velocity, $\theta_{*}$ the surface temperature scale and $f_{m}$ and $f_{h}$ stability functions often written in stable conditions as

$$
f_{m}=1+\beta_{m} \frac{z}{L}
$$

and

\footnotetext{
${ }^{1}$ Commonwealth Scientific and Industrial Research Organization LES model (Huang and Bou-Zeid 2013).

${ }^{2}$ Matlab LES model based on the locally-averaged scale-dependent dynamic SGS modelling approach(Basu and Porte-Agel 2006).
} 


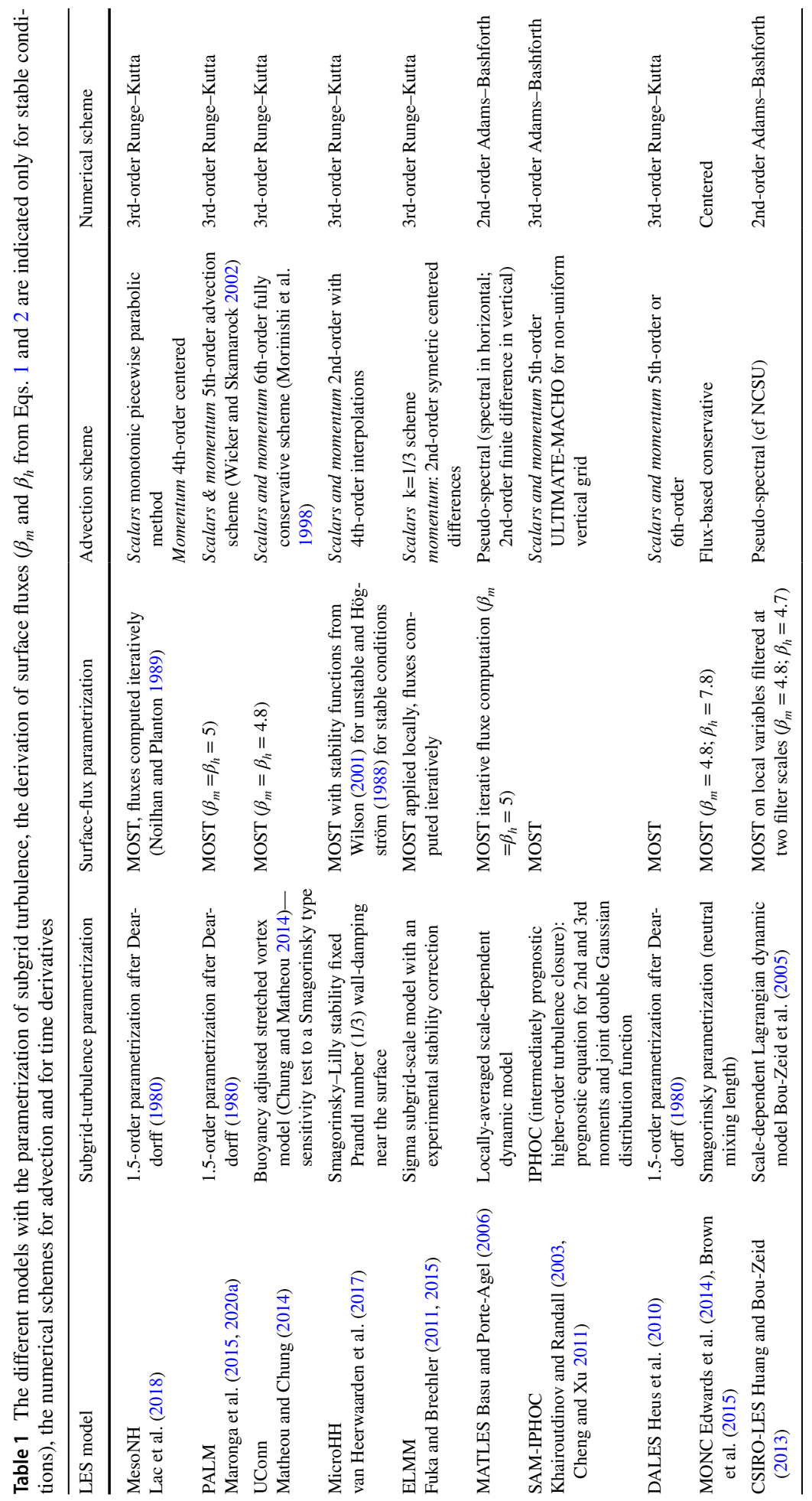




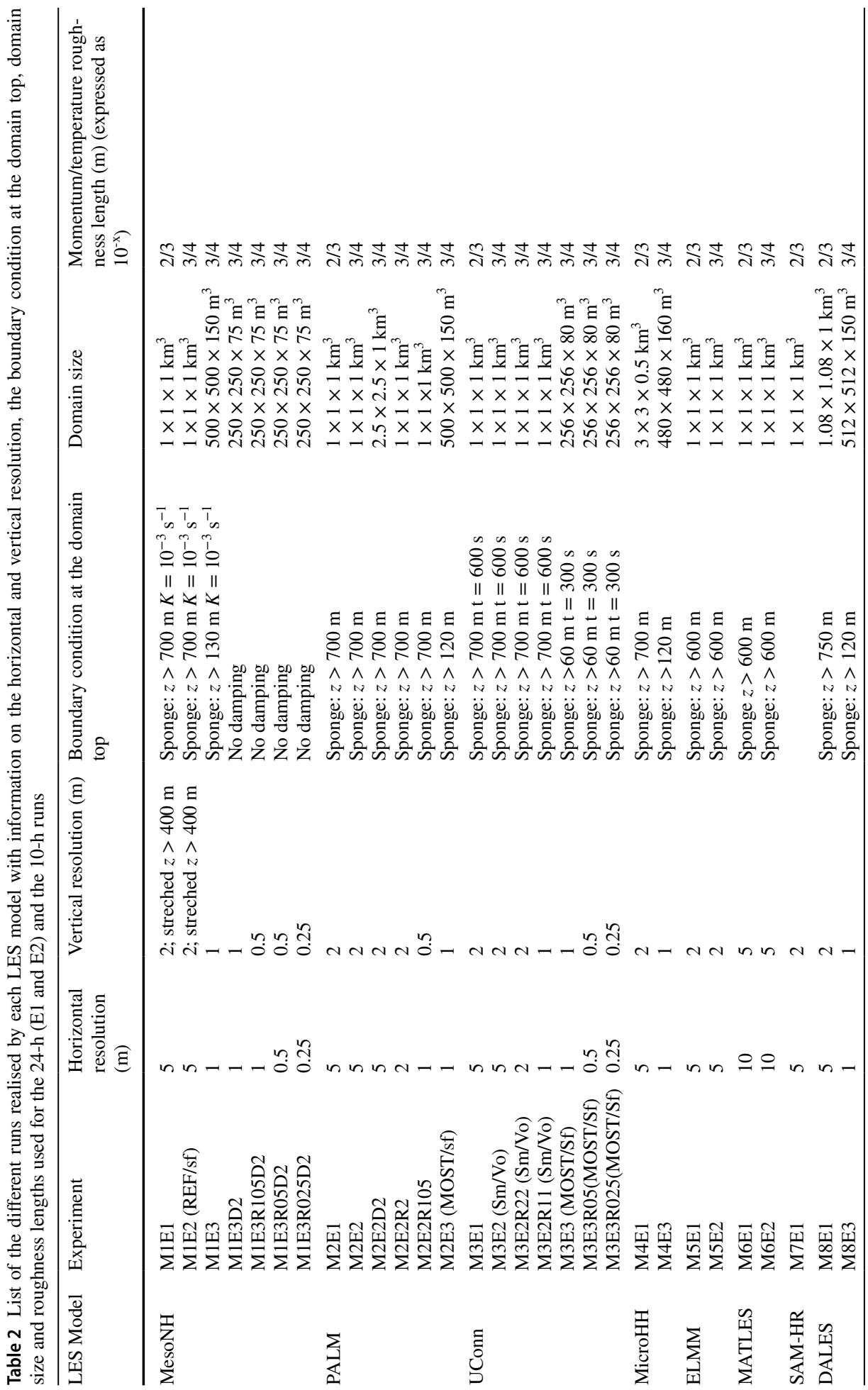




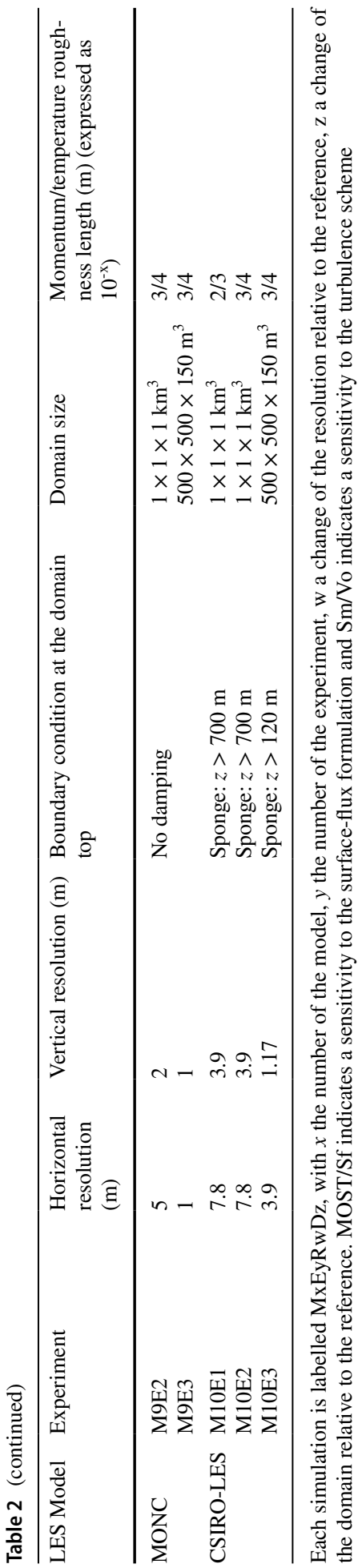




$$
f_{h}=1+\beta_{h} \frac{z}{L}
$$

where the $\beta_{m, h}$ coefficients have are model-specific values. Note that the values of the $\beta_{m, h}$ coefficients are not constrained in the present GABLS4 intercomparison and differ from one model to another (see Table 2 for more details). No moisture is included and therefore no microphysical parametrization is needed; radiation is also excluded to focus on turbulence.

The domain size was set to $1000 \times 1000 \times 1000 \mathrm{~m}^{3}$ with a horizontal resolution of $5 \mathrm{~m}$ and a vertical resolution of $2 \mathrm{~m}$ at least up to $400 \mathrm{~m}$ for experiments 1 and 2 . To prevent spurious reflection from the model top boundary, most models applied a Rayleigh damping above heights of 600-700 $\mathrm{m}$ where the prognostic variables are relaxed towards the largescale fields. Tests with a larger horizontal domain indicate that the prescribed domain size is sufficient (see Sect. 4). For runs starting at 1000 UTC (experiment 3), the domain was restricted to size of $500 \times 500 \times 150 \mathrm{~m}^{3}$, or even smaller depending on the models, with an isotropic grid of $1-\mathrm{m}$ resolution. The different sensitivity tests performed for each model are indicated in Table 2, as well as their configuration (resolution, domain and roughness lengths).

\subsection{Sensitivity Tests}

Several models contributed to the exercise with an ensemble of simulations, which enabled the analysis of the sensitivity of the results to the physical parameters and numerical configuration.

The sensitivity to the roughness length is first tested. Most models (MesoNH, ${ }^{3}$ PALM, ${ }^{4}$ UConn, MATLES, MONC, ${ }^{5}$ ELMM $^{6}$ and CSIRO) contributed with one simulation with $z_{0 m}=10^{-2} \mathrm{~m}$ and $z_{0 h}=10^{-3} \mathrm{~m}$ (experiment 1) and an additional one with $z_{0}=10^{-3} \mathrm{~m}$ and $z_{0 h}=10^{-4} \mathrm{~m}$ (experiment 2). Sensitivity to the SGS parametrization is addressed with one model. The UConn model was run with the exactly same configuration for runs of experiment 2 with an increasing grid resolution from 5 to $1 \mathrm{~m}$ (see Table 3) but with either a Smagorinsky SGS parametrization or a newly developed turbulence parametrization based on the buoyancy-adjusted stretched-vortex model (Chung and Matheou 2014). Three models investigated the sensitivity to the surface turbulent-flux parametrization. Experiment 3 was carried out using the MesoNH, PALM and UConn models with a prescribed relation to compute surface fluxes from the differences between the first-level and the surface temperature following Eqs. (1) and (2) with values of $\beta_{m}=4.8$ and $\beta_{h}=7.8$.

The sensitivity to the grid resolution has also been addressed. The PALM and UConn models were also used to perform additional simulations with a range of horizontal and vertical resolutions between $0.5 \mathrm{~m}$ and $5 \mathrm{~m}$ for experiment 2 (see Table 3). For experiment 3, the MesoNH and UConn models also had different horizontal and vertical resolutions, but note that these models were run on a smaller domain (see Table 3 and 3). Sensitivity to the size of the domain has been investigated with the help of two models. Several

\footnotetext{
3 The Mesoscale Non-Hydrostatic model (Lac et al. 2018).

4 The Parallelized Large-Eddy Simulation Model (Maronga et al. 2015, 2020a).

5 The Met Office NERC Cloud model, a re-write of the UK Met-Office Large-Eddy Model (Edwards et al. 2014, Brown et al. 2015).

${ }^{6}$ Extended Large-Eddy Microscale Model (Fuka and Brechler 2011, Fuka 2015).
} 


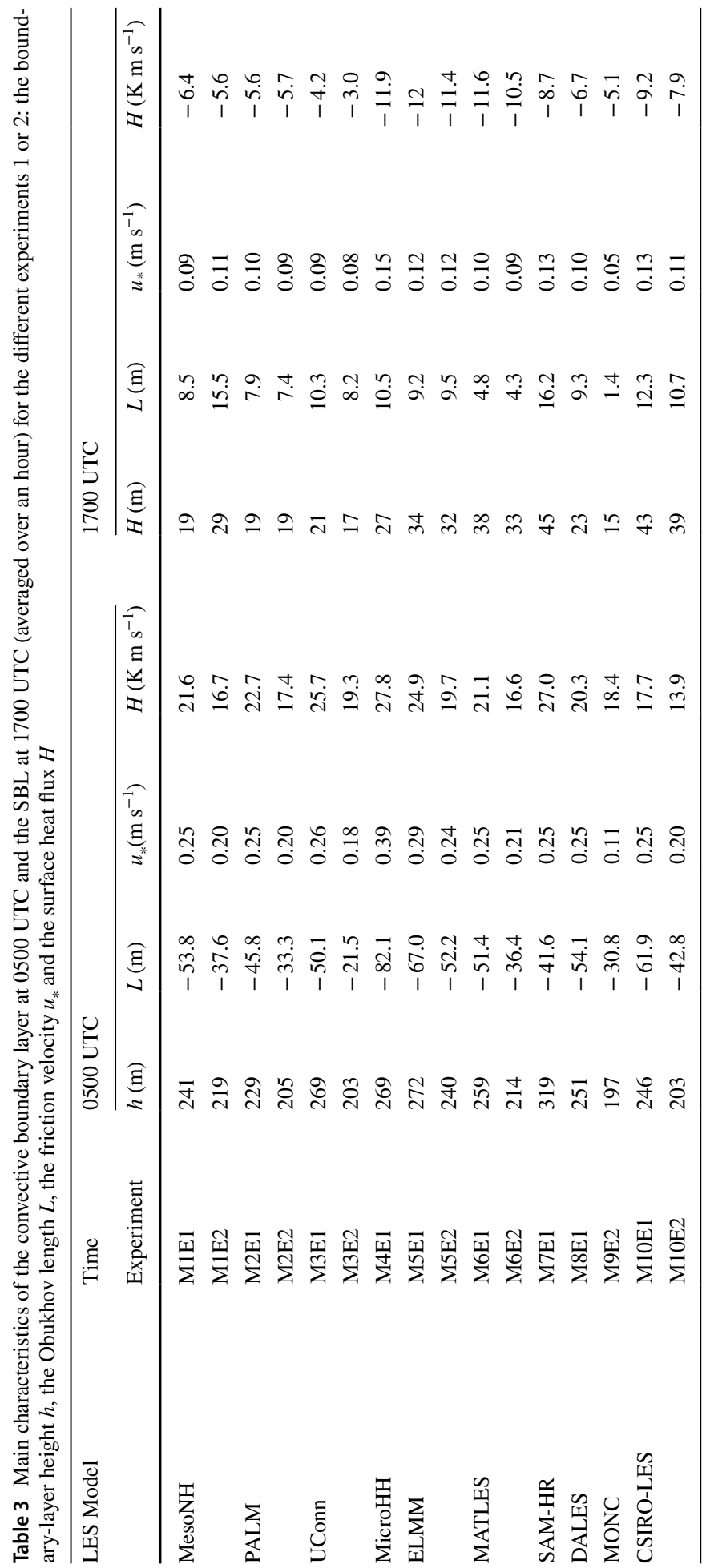




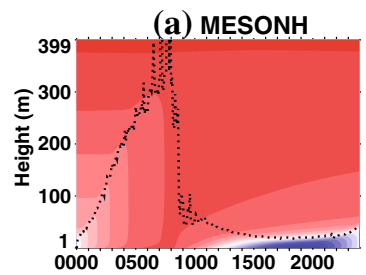

(d) MicroHH

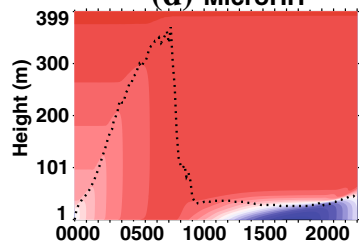

(g) ELMM

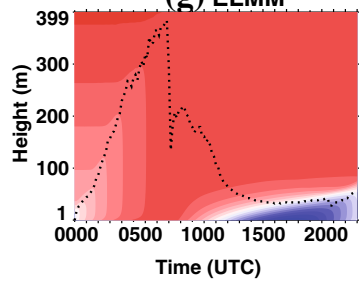

(b) PALM

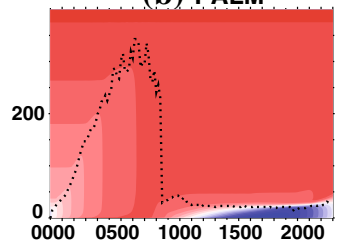

(e) DALES

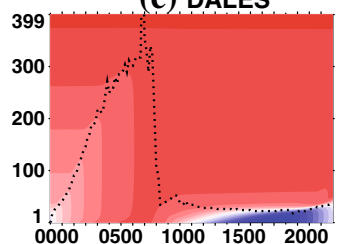

(h) CSIRO

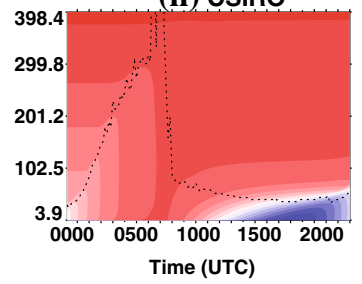

(c) UConn

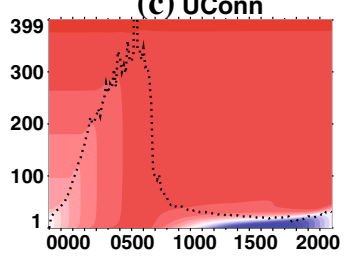

(f) SAM

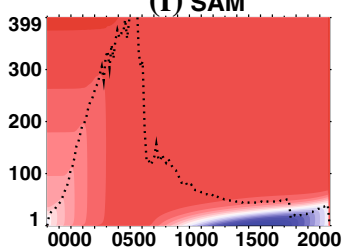

(i) MATLES

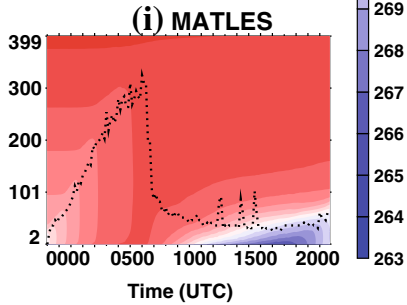

Fig. 2 Evolution of the vertical structure of potential temperature (see the colour bar to the right) for the different models (experiment 1) with the boundary-layer height (indicated by dotted lines) diagnosed as the level of the minimum value of turbulent vertical potential temperature flux in convective conditions or as the level where the shear is $<5 \%$ of its surface value in stable conditions (see text for more details). The $x$-axis indicates the UTC time and the $y$-axis indicates altitude $[\mathrm{m}]$ above ground level

domain sizes were used ranging from $2.5 \times 2.5 \times 1 \mathrm{~km}^{3}$ down to $0.25 \times 0.25 \times 0.075 \mathrm{~km}^{3}$. In particular, the PALM model provided a simulation with a $2.5 \times 2.5 \times 1 \mathrm{~km}^{3}$ domain and a $1 \times 1 \times 1 \mathrm{~km}^{3}$ for experiment 2 , the simulations with the $\mathrm{MicroHH}^{7}$ model were provided with a $3 \times 3 \times 0.5 \mathrm{~km}^{3}$ domain for experiment 1 and the MesoNH model provided two simulations with $0.5 \times 0.5 \times 0.15 \mathrm{~km}^{3}$ and $0.25 \times 0.25 \times 0.075 \mathrm{~km}^{3}$ domains for experiment 3 . The sensitivity to the starting time has also been analyzed. The MesoNH and MicroHH models initiated either from the profile prescribed for experiment 3 (ensemble mean at 1000 UTC) or from the initial profiles at 0000 UTC in order to assess the sensitivity to the different initializations.

The results of these sensitivity tests are described in Sect. 4.

\footnotetext{
7 Computational fluid dynamics code made for direct numerical simulation and large-eddy simulation (Van Heerwaarden et al. 2018).
} 


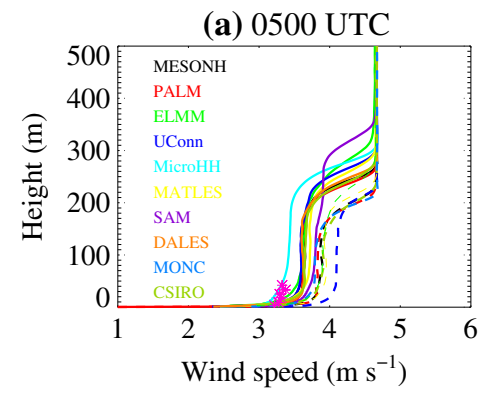

(c) 1700 UTC

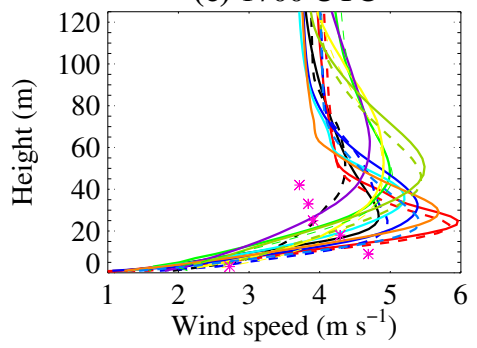

(b) 0500 UTC

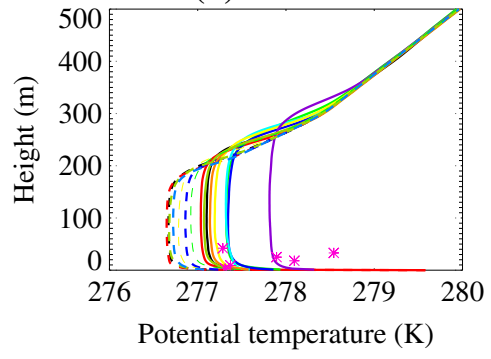

(d) 1700 UTC

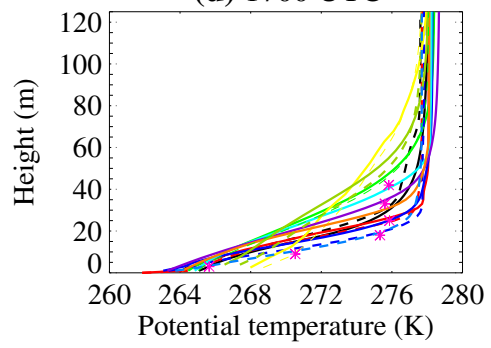

Fig. 3 Vertical profiles of $(\mathbf{a}, \mathbf{c})$ wind speed and $(\mathbf{b}, \mathbf{d})$ potential temperature during daytime at 0500 UTC (1300 local time) (a, b) and night-time at 1700 UTC (0100 local time) (c, d). The observations from the tower, here and in the following figures, are indicated by pink stars. Note that tower measurements merely illustrate an expected behaviour but we do not expect a real match due to the assumptions realized in the definition of the case. Simulations with $z_{0 m}=10^{-2} \mathrm{~m}$ (experiment 1) are shown with full lines and those with $z_{0 m}=10^{-3} \mathrm{~m}$ (experiment 2 ) are shown with dashed lines

\section{Results}

\subsection{Diurnal Cycle}

Figure 2 presents the evolution of the vertical structure of potential temperature for experiment 1 (nine models). All models represent the convective boundary layer developing during the first $7 \mathrm{~h}$ of the simulations, with a boundary-layer height defined as the height of the minimum of the vertical turbulent heat flux, reaching 300-400 m. This is consistent with the range of summer convective-boundary-layer heights observed at Dome C as reported, for example, by sodar observations (Casasanta et al. 2014).

Figure $3 \mathrm{a}, \mathrm{b}$ shows the relatively good agreement between models in representing the convective boundary layer, although the SAM model displays stronger convection with a warmer $(0.5 \mathrm{~K})$ and higher boundary layer, consistent with its larger sensible heat flux and larger TKE (Fig. 4). Focusing on the models that use $z_{0 m}=10^{-2} \mathrm{~m}$ (shown in full lines), the spread between the other models is $0.3 \mathrm{~K}$ for the boundary-layer potential temperature and $20 \mathrm{~m}$ for the boundary-lay er height. With regard to the horizontal structures, the distribution of temperature fluctuations and turbulence spectra in the boundary layer indicate good agreement between observations and simulations for the convective period (not shown); however, the data reveal a greater spread during stable conditions. Indeed, after $10 \mathrm{~h}$, a SBL develops with a height that varies between models with the highest values for the CSIRO and MATLES models, which have the lowest spatial resolution (see Fig. 2). This is 


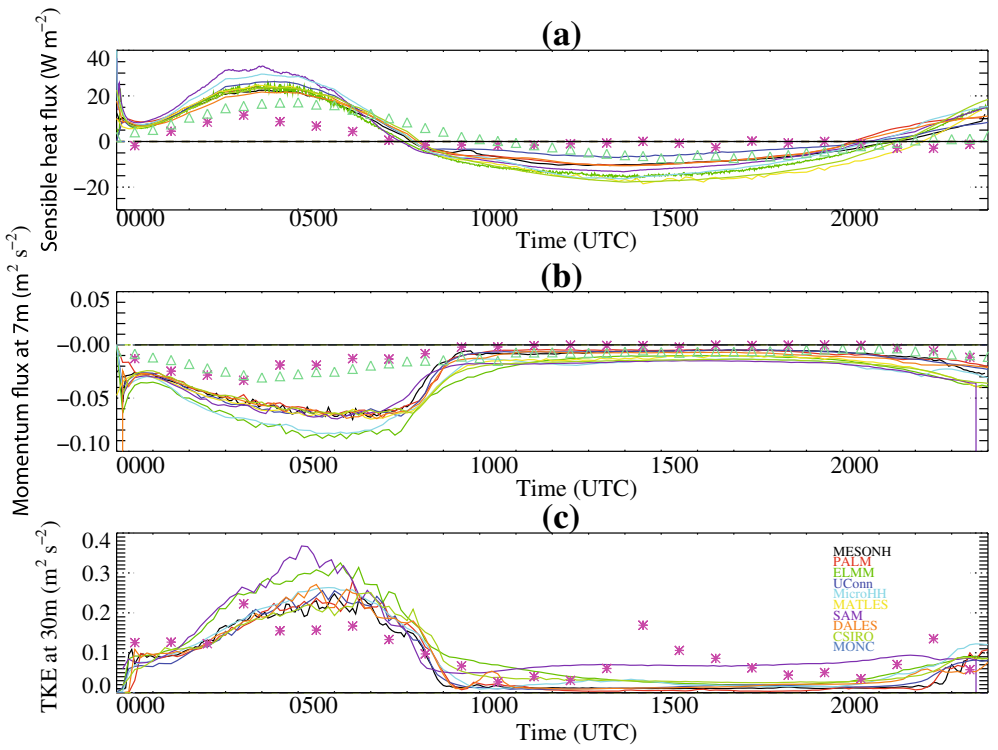

Fig. 4 Evolution of a surface sensible heat flux (positive into the atmosphere), b momentum flux at $7 \mathrm{~m}, \mathbf{c}$ turbulence kinetic energy at $30 \mathrm{~m}$ for all the LES results as well as observations, either derived from sonicanenometer measurements at $7 \mathrm{~m}$ or $30 \mathrm{~m}$ above the surface as pink stars, or derived from the relationship between fluxes and gradients as green triangles, representative of $1.5 \mathrm{~m}$ above the surface. Only simulations with $z_{0 m}=10^{-2} \mathrm{~m}$ (experiment 1$)$ are shown here

also evident from the vertical profiles at 1700 UTC (Fig. 3c, d) showing a relatively large spread of the peak of the low-level nocturnal jet, the boundary-layer height, as well as the stratification observed at the top of the boundary layer. Part of the differences between observations and the LES models may be due to the definition of the forcing, which have been simplified in the studied case.

Figure $4 \mathrm{a}$ shows the surface sensible heat fluxes as computed by the individual models (only the surface temperature is prescribed). The spread during convective conditions reaches about $10 \mathrm{~W} \mathrm{~m}^{-2}$, which is of the same order of magnitude as the maximum of the ensemble mean of $20 \mathrm{~W} \mathrm{~m}^{-2}$; during stable conditions, the spread still reaches $10 \mathrm{~W} \mathrm{~m}^{-2}$, which is equal, in absolute value, to the ensemble mean. The simulated fluxes agree more or less with observations given the uncertainties of in situ turbulence measurements (and the fact that the observations correspond to flux estimates at either $1.5 \mathrm{~m}$ or $7 \mathrm{~m}$ depending on the method of estimates) but issues with the applicability of MOST in such stable conditions may also explain some departure (Mahrt 2008, 2010). The momentum flux at $7 \mathrm{~m}$ (Fig. 4b and Table 3) in experiment 1 varies from $-0.09 \mathrm{~m}^{2} \mathrm{~s}^{-2}$ to zero depending on the model with a mean value during convective conditions of $-0.065 \mathrm{~m}^{2} \mathrm{~s}^{-2}$ and a very small spread, apart from two diverging models; this is larger than the observed value of $-0.025 \mathrm{~m}^{2} \mathrm{~s}^{-2}$. The total (resolved plus subgrid) TKE (Fig. 4c) at $30 \mathrm{~m}$ reaches $0.2-0.35 \mathrm{~m}^{2} \mathrm{~s}^{-2}$ depending on the model, and is also overestimated compared with observations. Using reduced prescribed momentum roughness length of $10^{-3} \mathrm{~m}$ (experiment 2 and Table 3) reduces surface sensible heat fluxes, friction velocity at $7 \mathrm{~m}$ and TKE at $30 \mathrm{~m}$ mainly during convective conditions, with values closer to observations (not shown). It is worth remembering that the mean estimated roughness length derived from observations is also close to $10^{-3} \mathrm{~m}$ (Vignon et al. 2017b). In the following, we focus on the analysis of 

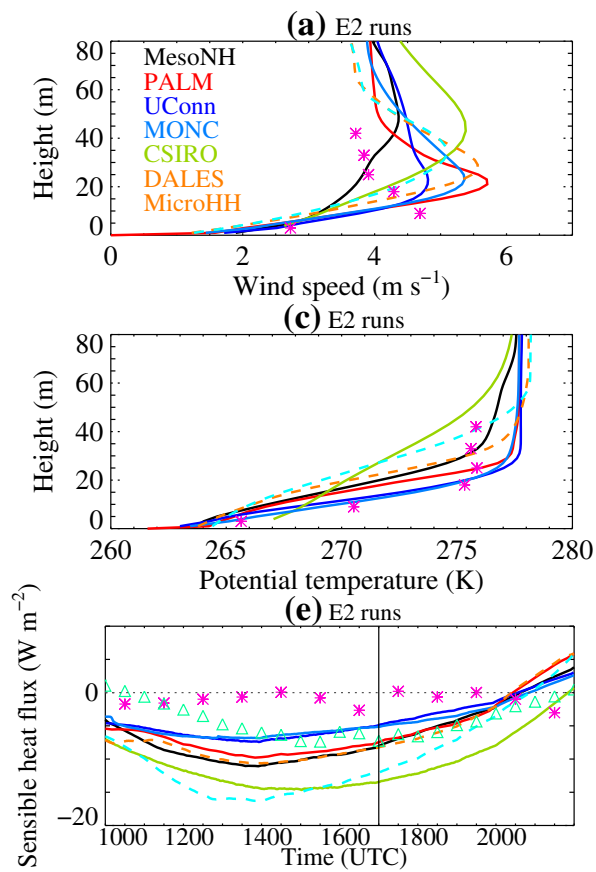

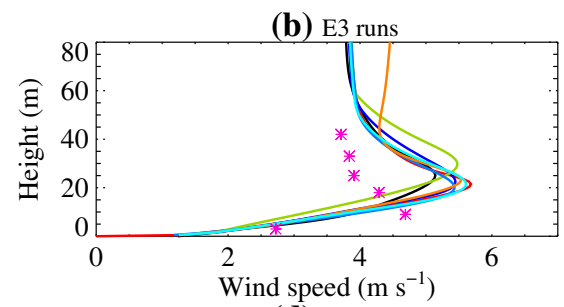

(d) E3 runs
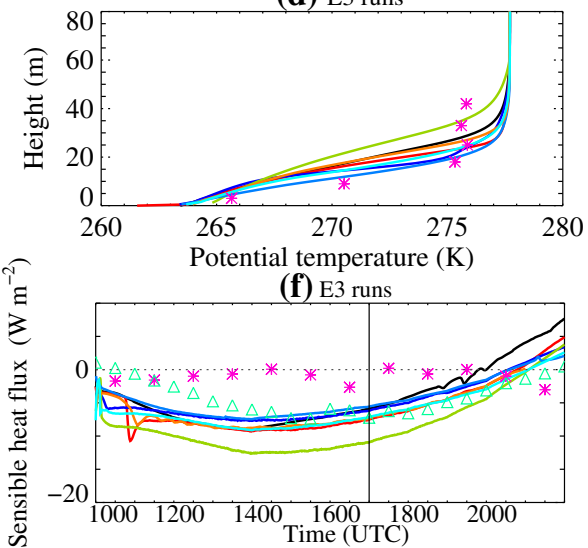

Fig. 5 Vertical profiles at 1700 UTC of $(\mathbf{a}, \mathbf{b})$ wind speed and $(\mathbf{c}, \mathbf{d})$ potential temperature from the experiment $2(\mathbf{a}, \mathbf{c})$ and from experiment $3(\mathbf{b}, \mathbf{d})$ as well as the evolution of the surface sensible heat flux from 1000 to 2200 UTC from (e) experiment 2 and (f) experiment 3. Observations from the tower are indicated by pink stars in panels a-d, which correspond to meteorological instruments and pink stars for panels e-f, which correspond to sonic-anenometers. The green triangles indicate values derived from the relationship between fluxes and gradients. The vertical black line in Figs. 5e-f indicates the time at 1700 UTC. The DALES and MicroHH models are indicated by dashed lines on the left figures as those models only contributed to experiment 1 (larger roughness length) and the comparison with experiment 3 should be treated with caution as different roughness lengths are used

runs using this value of the roughness length (experiments 2 and 3). The simulation spread is reduced during convective conditions but not during stable conditions.

\subsection{Stable Period}

Below, we concentrate on the analysis of the stable conditions, i.e., the period when the sun is very low above the horizon and the boundary layer is stably stratified. According to the literature, a 5-m horizontal grid spacing is not fine enough to correctly represent the very shallow boundary layer during the stable conditions (see Beare et al. 2006; Sullivan et al. 2016 among others). Indeed, Figs. 2, 3, and 4 indicate an absence of convergence between the LES models for the stable period, which may partly be explained by too coarse a resolution in the simulations.

Figure 5 presents the vertical profiles of potential temperature and wind speed for the models involved in both experiments 2 and 3 (which differ in resolution and initial profiles). The spread among the simulations is clearly reduced from experiment $2(\Delta x=5 \mathrm{~m}$, $\Delta z=2 \mathrm{~m})$ to experiment $3(\Delta x=\Delta z=1 \mathrm{~m})$ both in terms of intensity and height of the low-level jet, as well as regarding the height of the maximum positive gradient of potential 


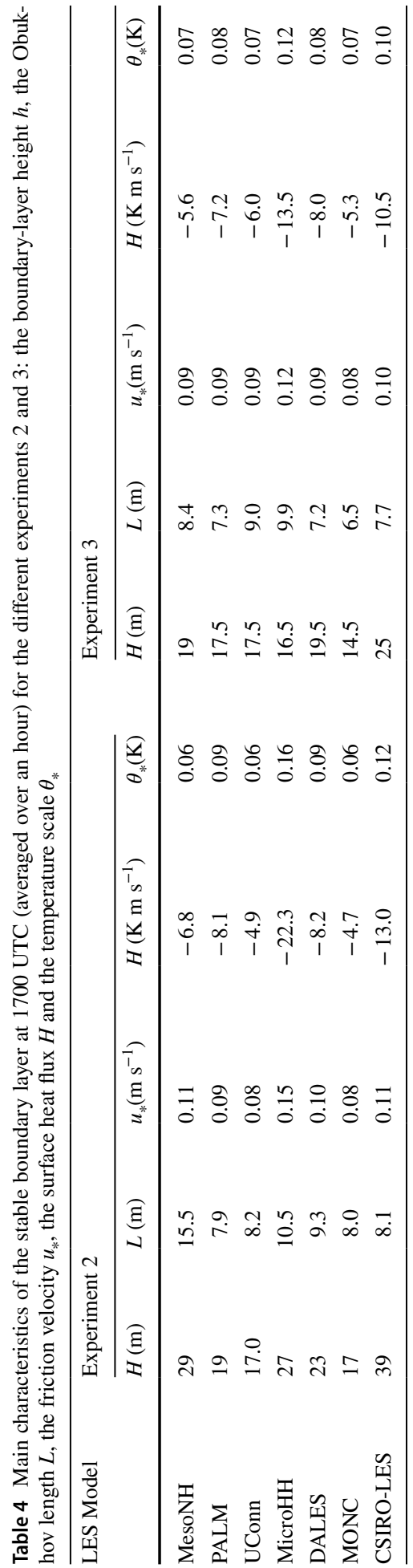




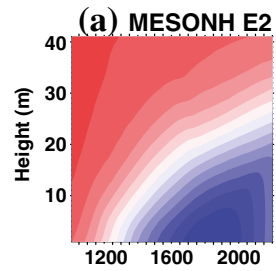

(e) UConn E2

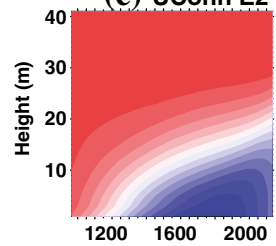

(m) CSIRO E2

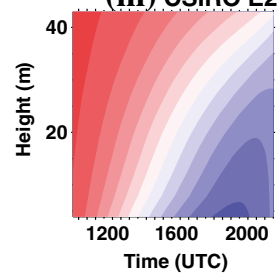

(b) MESONH E3

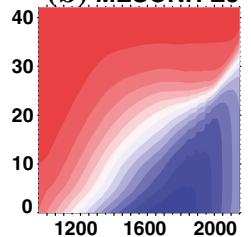

(f) UConn E3

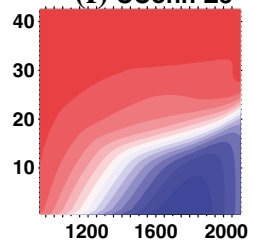

(n) CSIRO E3

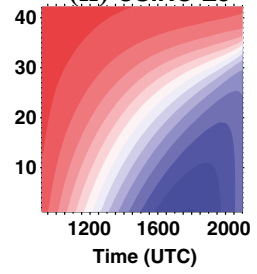

(c) PALM E2

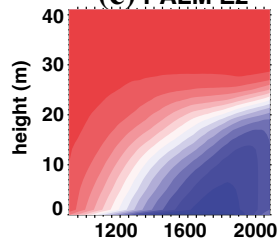

(g) MONC E2

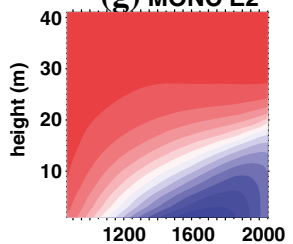

(o) Tower observations

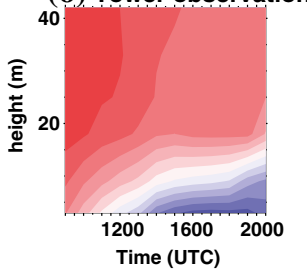

(d) PALM E3

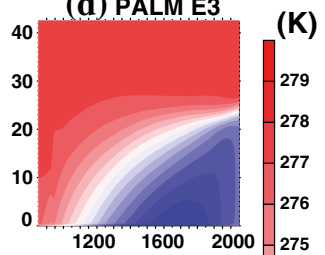

(h) MONC E3

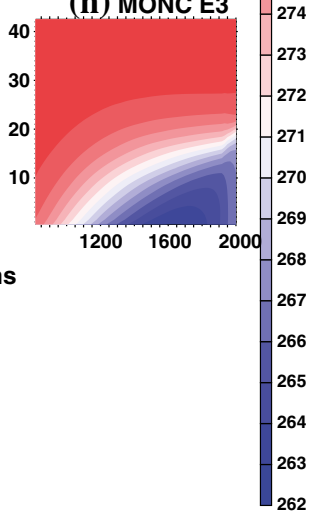

Fig. 6 Evolution of the vertical structure of potential temperature during night-time from experiment 2 (a, $\mathbf{c}, \mathbf{e}, \mathbf{g}, \mathbf{i}, \mathbf{k}, \mathbf{m})$ and experiment $3(\mathbf{b}, \mathbf{d}, \mathbf{f}, \mathbf{h}, \mathbf{j}, \mathbf{l}, \mathbf{n})$ as well as the tower observations (o). The time on the $x$-axis is presented in UTC

temperature. For example, the standard deviation at $20 \mathrm{~m}$ reduces from 0.52 to $0.28 \mathrm{~m} \mathrm{~s}^{-1}$ for the wind speed and from 2.53 to $1.88 \mathrm{~K}$ for the potential temperature. The spread is also reduced for the turbulent sensible heat flux from $\approx 10$ to $5 \mathrm{~W} \mathrm{~m}^{-2}$.

Table 4 also indicates a reduction of spread in the main turbulent characteristics (boundary-layer height, friction velocity, Obukhov length) for those two experiments, which is caused by the increased resolution rather than by the initial conditions. Indeed, further sensitivity tests revealed that the reduction of the spread is not explained by different initial conditions (not shown). Figure 6 presents the evolution of the vertical profiles of the potential temperature for $z<42 \mathrm{~m}$, in comparison with the observations collected from the tower at Dome C. It is evident that the SBL tends to be thinner and to have a stronger inversion at the top for simulations of higher resolution (it is slightly less evident for the UConn and PALM models), which is in agreement with previous results (Sullivan et al. 2016; Van Stratum and Stevens 2015 among others). Also, the models overestimate the boundarylayer height compared with observations but this may be due to the absence of subsidence in the simulations (Vignon et al. 2017c). The spread in model results is larger when focusing on variances and covariances for both experiments as illustrated by the evolution of TKE and the turbulent heat flux (Fig. 7), although there is also a clear reduction of the spread in the highly resolved simulations. Dotted lines in Fig. 7 show the subgrid component of the TKE and indicate a strong decrease of its contribution to the total TKE in the highly resolved simulations. For the TKE, two estimates are available from observations, 
(a) E2 runs

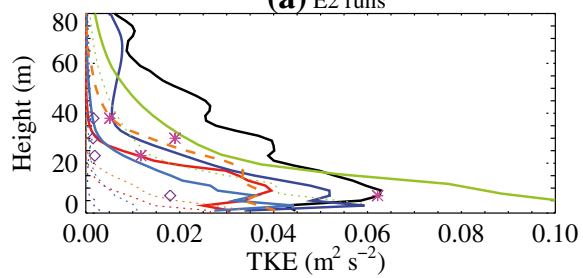

(c) E2 runs

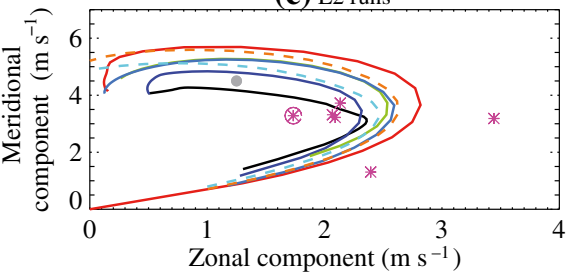

(e) E2 runs

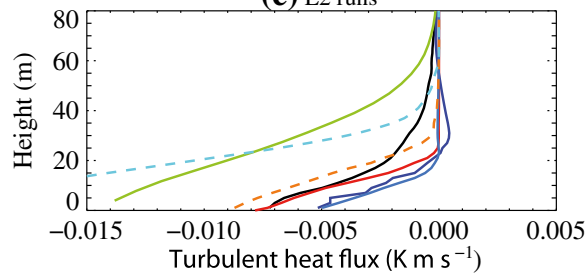

(b) E3 runs

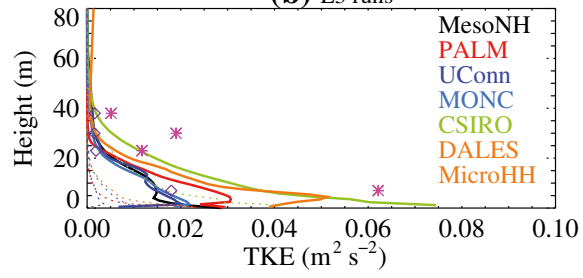

(d) E3 runs

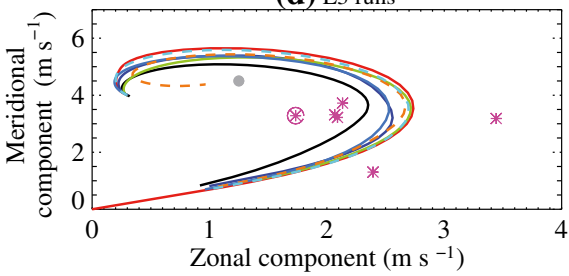

(f) E3 runs

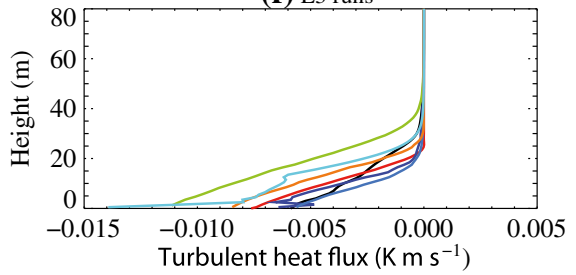

Fig. 7 Vertical profiles at 1700 UTC of (a, b) turbulence kinetic energy (full lines) and subgrid turbulence kinetic energy (dotted lines) and (e, f) turbulent potential temperature flux as well as (c, d) wind veer for the first $80 \mathrm{~m}$ above the surface from experiment 2 (a, $\mathbf{c}$ and e) and from experiment 3 (b, d and f). Observations from the tower are indicated by pink stars in panels $\mathbf{a}-\mathbf{d}$, which correspond to meteorological instruments and pink stars for panels e-f, which correspond to sonic-anenometers. The green triangles indicate values derived from the relationship between fluxes and gradients. The vertical black line in Figs. 5e-f indicates the time at 1700 UTC. The DALES and MicroHH models are indicated by dashed lines on the left figures as those models only contributed to experiment 1 (larger roughness lengths) and the comparison with experiment 3 should be treated with caution as different roughness lengths are used
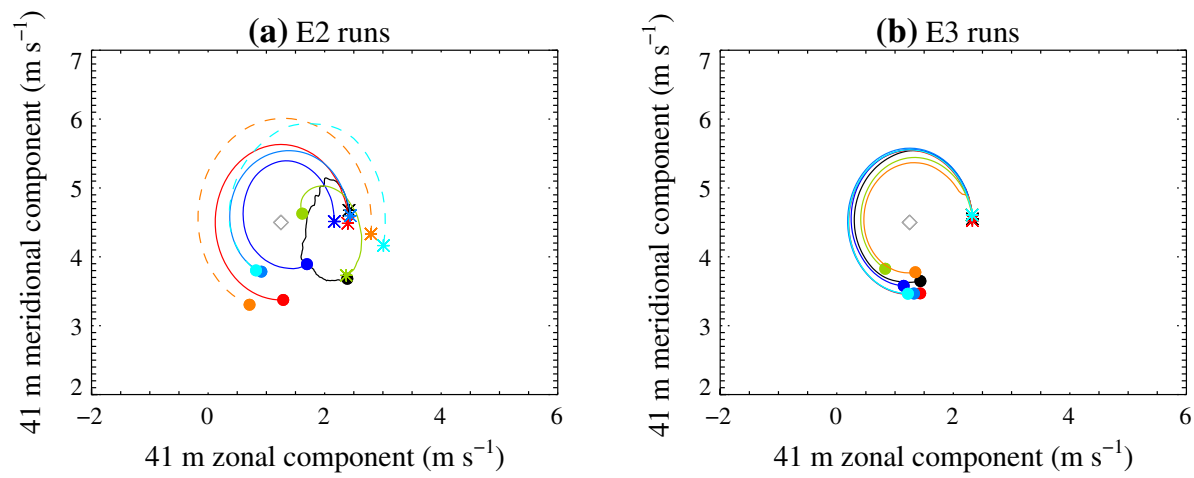

Fig. 8 Hodograph of the simulated wind speed at $41 \mathrm{~m}$ in experiment 2 (left) and experiment 3 (right). The DALES and MicroHH models are indicated by dashed lines on the left figures as those models only contributed to experiment 1 (larger roughness lengths) and the comparison with experiment 3 should be treated with caution as different roughness lengths are used 
(a) E2 runs

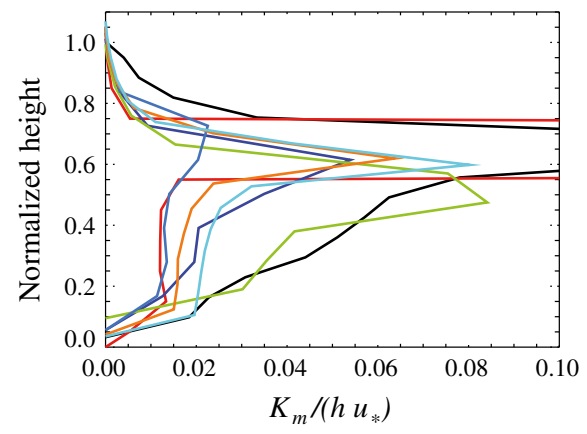

(c) E3 runs

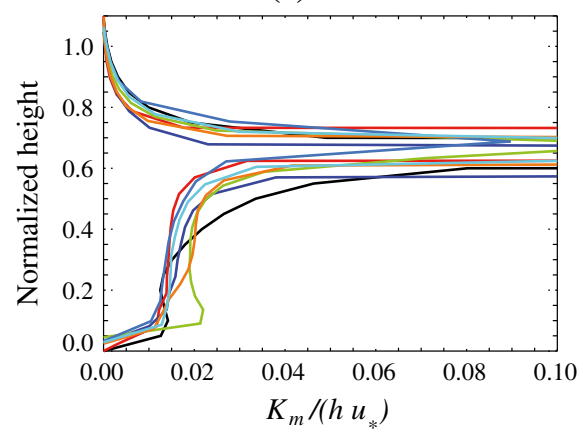

(b) E2 runs

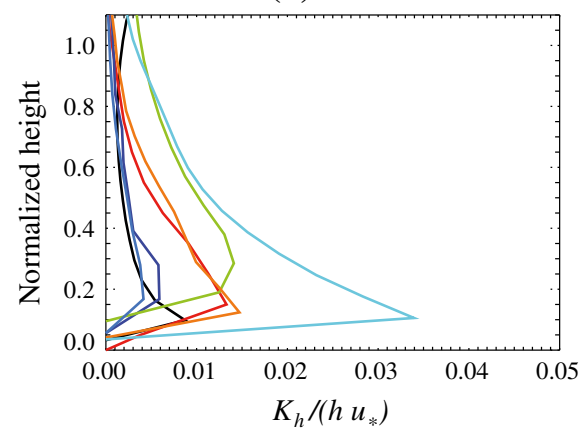

(d) E3 runs

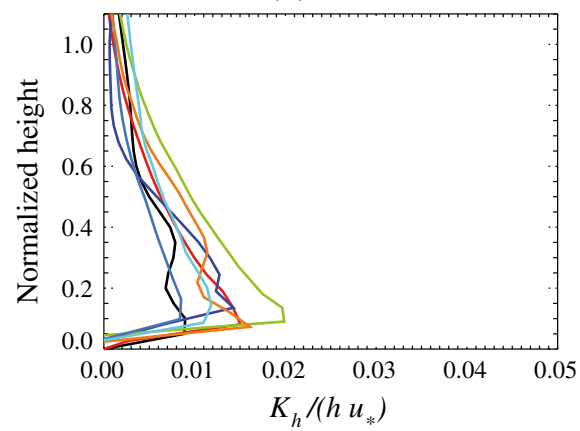

Fig. 9 Vertical profiles of $(\mathbf{a}, \mathbf{c})$ momentum and $(\mathbf{b}, \mathbf{d})$ heat effective diffusivities normalized by the boundary-layer height (h) and the surface friction velocity at 1700 UTC for experiment 2 in (a, b) and experiment 3 in $(\mathbf{c}, \mathbf{d})$. The vertical axis is also normalized by the boundary-layer height

either from turbulence data with a 200-s high-pass filter ${ }^{8}$ or from raw turbulence data. The difference between the two estimates may reveal the existence of waves, large eddies or sub-mesoscale eddies that contribute significantly to the turbulence kinetic energy. Figure 7 also shows the evolution of the velocity components with height, while the vertical variation of the wind speed from simulations with a resolution of $1 \mathrm{~m}$ shows closer agreement than those from more coarsely resolved simulations. Some differences persist, with the Meso-NH model having the lowest wind speed and the PALM model the highest one. Figure 8 presents the evolution through time of the wind speed at $41 \mathrm{~m}$ with again a better agreement between the simulations of experiment 3 than those of experiment 2. As shown in Vignon et al. (2017c, their Fig. 8), observations clearly indicate an inertial oscillation after the turbulence decay in the evening transition with a frequency of the order of $12 \mathrm{~h}$ as expected from the theory and the latitude of $75 \mathrm{~S}$ of Dome $\mathrm{C}$. The simulations agree with the observations for the inertial oscillation and the period (the geostrophic wind speed used in the forcing is indicated by the grey square). The reduction of spread for experiment 3 is probably due to the use of the same initialization just at the moment of turbulence

\footnotetext{
${ }^{8}$ This is the classical cut-off frequency used for flux computation, and, using ogive computation, it was checked that this is appropriate for turbulence measurements in this situation.
} 
(a)

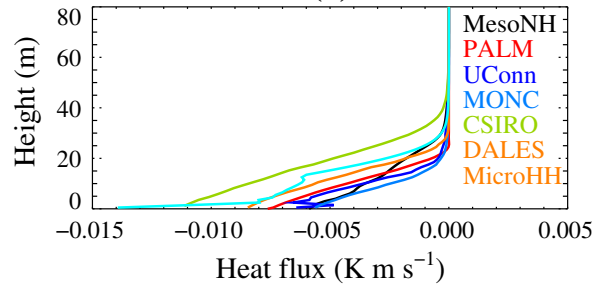

(c)

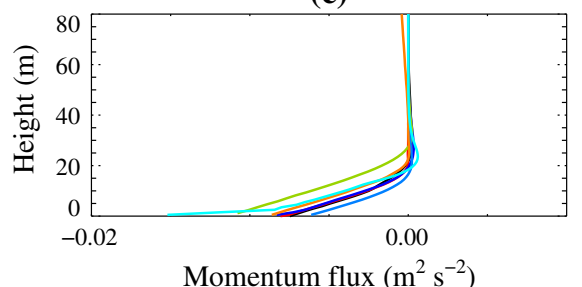

(e)

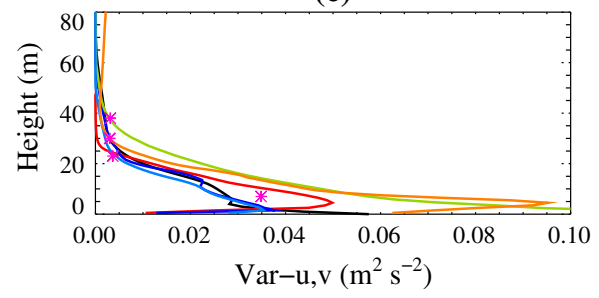

(b)

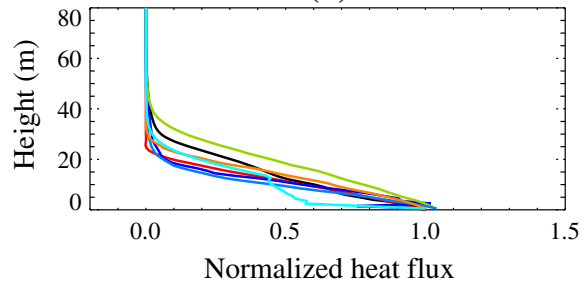

(d)

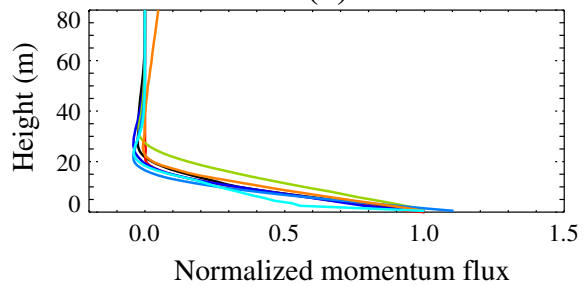

(f)

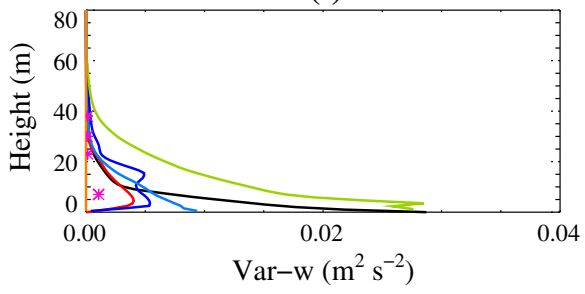

Fig. 10 Vertical profiles at 1700 UTC of the raw vertical flux of potential temperature (a), normalized by the surface flux (b), the raw vertical flux of horizontal momentum (c), normalized by the surface flux (d), variance of the horizontal velocity components (e) and the vertical component (f) from experiment 3 as well as the tower observations (pink stars)

decay in opposition to experiment 2 where the different convective boundary layers generate different wind-speed profiles. Figure 9 presents the effective momentum and heat diffusivities normalized by the boundary-layer height and the friction velocity and shows that the spread is also reduced between experiment 2 runs and experiment 3 runs. The profiles differ significantly from those of the GABLS1 experiment (Beare et al. 2006) in particular concerning the shapes of the profiles for momentum due in particular to an almost null vertical gradient of wind speed.

In the following, we focus only on the results of experiment 3 that show much closer agreement between the different models. Figure 10 shows the vertical profiles of the (a) turbulent heat flux and (c) horizontal momentum flux, and the respective fluxes normalized by their surface values ( $b$ and $d$ ), where it is evident that the remaining spread is largely explained by differences in surface fluxes since, when normalized, the curves almost converge; we also note close to linear profiles. In particular, the MONC model produces a particularly low wind stress at the surface, which is also visible in Fig. 4b, but the model has a similar transport of momentum compared with the other LES models when normalized. Figure 10e, f also shows the contribution to the turbulence kinetic energy of the variance of the horizontal velocity components and the variance of the vertical velocity component. As expected in stable conditions, the contribution of the horizontal velocity 
components (var- $u, v)$ is stronger than the contribution of the vertical velocity component (var-w), which is consistent with Huang and Bou-Zeid (2013), who found that turbulence is much more energetic horizontally than vertically under very stable conditions, causing 'sandwiched' coherent structures (Chung and Matheou 2012, Matheou and Chung 2012). Note, however, a large spread among models in the variance of the velocity components.

Although, the spread among the LES models is reduced for the experiment 3 set-up, there are still some discrepancies in terms of horizontal variability. This was in particular investigated by comparing the distribution of the potential temperature anomalies for five different vertical levels ranging from $7 \mathrm{~m}$ to $38 \mathrm{~m}$ above the surface, but this is also true for the anomalies of the three velocity components (not shown). Observations indicate that horizontal variability is large only at $7 \mathrm{~m}$ and strongly reduced at $23 \mathrm{~m}$. Unfortunately, no information from the observations is provided between $7 \mathrm{~m}$ and $23 \mathrm{~m}$. The CSIRO and DALES $^{9}$ models give the largest variability at all levels except $38 \mathrm{~m}$, while the MesoNH, MONC and UConn models show the largest horizontal variability at $14 \mathrm{~m}$. For the horizontal variability of the horizontal velocity components, the maximum is simulated close to the surface for all the models (not shown). The disagreement with the observations is consistent with the LES approach predicting deeper boundary layers than observed.

\section{Sensitivity Tests}

This section summarizes the main conclusions of the different sensitivity tests carried out in this intercomparison. We first investigate the sensitivity to the numerical configuration (time of initialization, size of the domain or resolution) and then assess the sensitivity to the physical parameters (roughness lengths, turbulence parametrization and surface-flux parametrization).

\subsection{Initial Profile}

Starting a simulation at either 0000 UTC (0800 LT) or 1000 UTC (1800 LT) had very little impact on the representation of the SBL for both MesoNH and UConn runs (not shown), which may be counter-intuitive as we may think that the way the convective boundary layer is reproduced (especially just before the convective-stable transition) matters for the rest of the period with stable conditions. However, this may also be explained by the fact that there is not much spread among the different LES models after $10 \mathrm{~h}$ and, therefore, the initial conditions at 1000 UTC do not differ much from the thermodynamic conditions encountered in any LES runs.

\subsection{Grid Resolution}

The PALM and UConn models ran experiment 2 with increasing resolution from 5 to $1 \mathrm{~m}$ (see Table 2) and the MesoNH and UConn models ran experiment 3 with increasing resolution from 1 to $0.25 \mathrm{~m}$ (see Table 2). The PALM simulations show relatively

${ }^{9}$ Dutch Atmosphere Large-Eddy Simulation (Heus et al. 2010). 

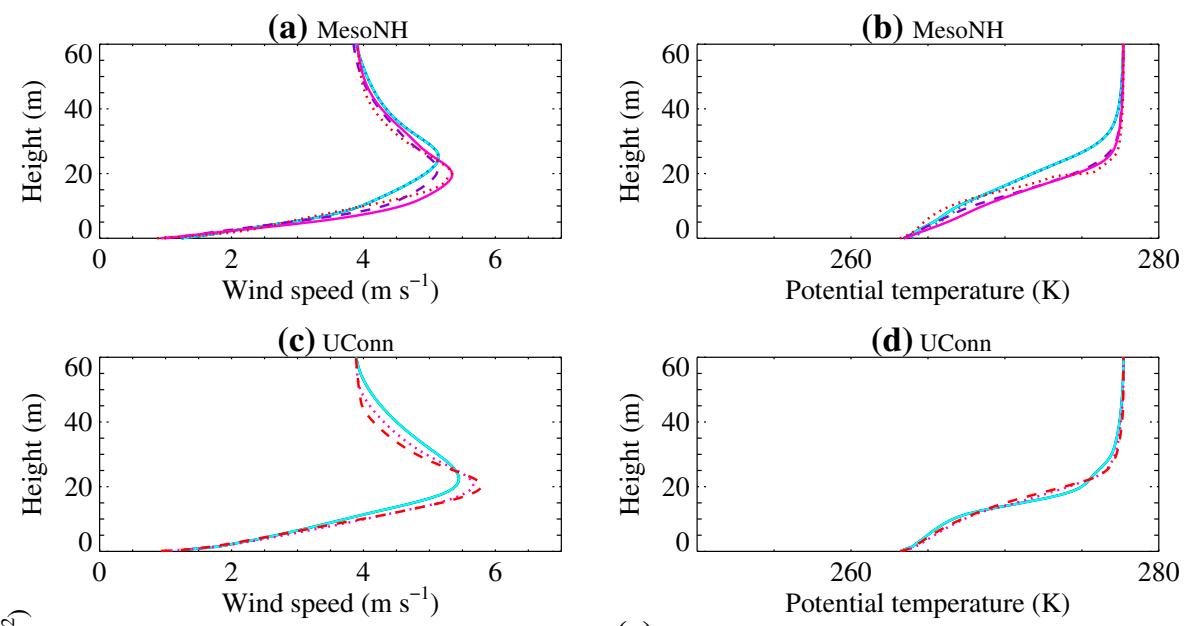

?

(e)

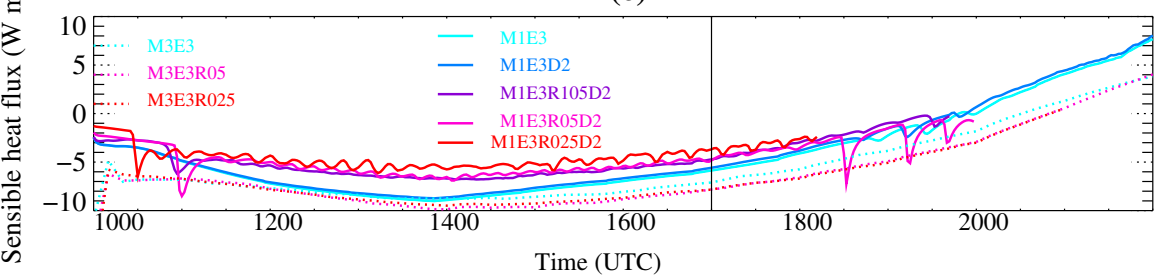

Fig. 11 Vertical profiles at 1700 UTC of $(\mathbf{a}, \mathbf{c})$ wind speed and $(\mathbf{b}, \mathbf{d})$ potential temperature at 1700 UTC for $(\mathbf{a}, \mathbf{b})$ the MesoNH model or (c, $\mathbf{d})$ the UConn model for various horizontal or vertical resolutions (see legend and Table 2 for details on the resolution) and (e) time series of the surface sensible heat fluxes

little sensitivity to the resolution and results are similar from experiments 2 to 3 , with the UConn simulations showing more differences among the different resolution tests in experiment 2. Figure 11 shows the resulting vertical profiles at 1700 UTC for the runs of experiment 3 focusing on the stable conditions. Convergence of the simulations, according to the mean profiles, is obtained for $0.5 \mathrm{~m}$ for both the UConn and MesoNH models. For the MesoNH model, running the simulation with a higher resolution leads to a shallower SBL and low-level jet, and weaker surface sensible heat fluxes, similar to that reported in Sullivan et al. (2016). It is worth noting that, for the MesoNH model, the increase in vertical resolution from 1 to $0.5 \mathrm{~m}$ has more impact than increasing the horizontal resolution from 1 to $0.5 \mathrm{~m}$, possibly because a higher vertical resolution improves the representation of the vertical gradients, which are rather strong under stable conditions, and of the turbulent structures, which become anisotropic or compressed in the vertical direction by buoyancy effects. For the second-order moments (Fig. 12), the convergence is obtained at $0.5 \mathrm{~m}$ for the UConn model as the $0.25 \mathrm{~m}$ has exactly the same results but this is not yet evident in the MesoNH results; this shows that grid convergence is model-specific. Note, moreover, that the results of Sullivan et al. (2016), Maronga et al. (2020) and van der Linden et al. (2019) indicate that grid convergence is not reached at grid spacings of $0.33 \mathrm{~m}$ and 
(a) $\mathrm{MesoNH}$

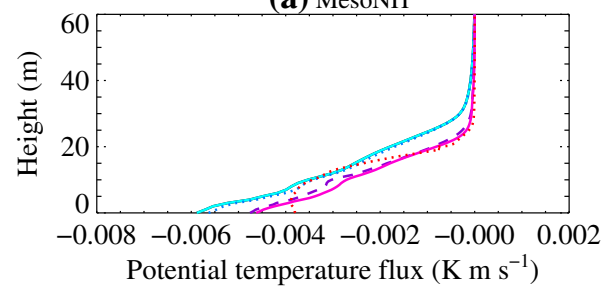

(c) MesoNH

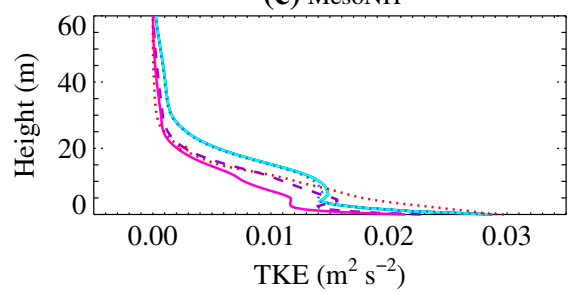

(e) MesoNH

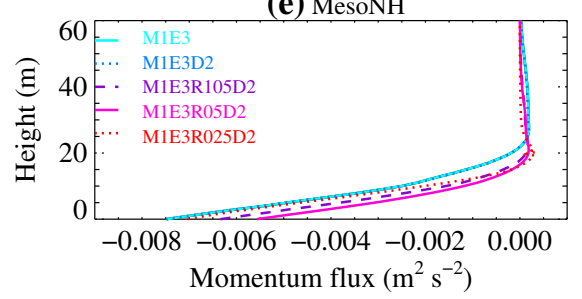

(b) UConn

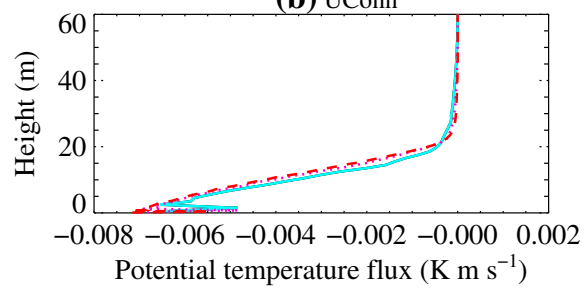

(d) UConn

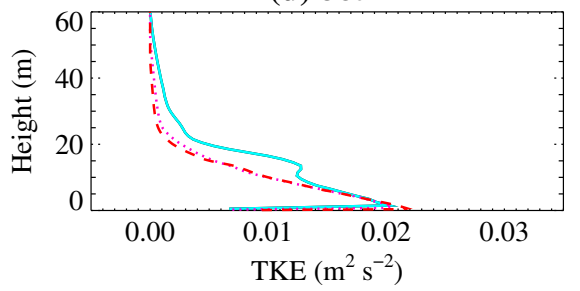

(f) UConn

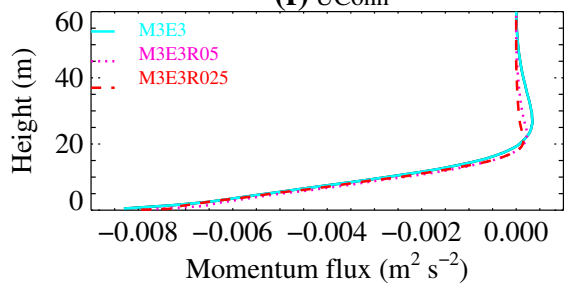

Fig. 12 Vertical profiles at 1700 UTC of $(\mathbf{a}, \mathbf{b})$ potential temperature turbulent flux, $(\mathbf{c}, \mathbf{d})$ turbulence kinetic energy and (e, f) momentum flux at 1700 UTC for $(\mathbf{a}, \mathbf{c}, \mathbf{e})$ the MesoNH model or (b, d, f) the UConn model for various horizontal or vertical resolutions (see legend and Table 2 for details on the resolution)

$0.5 \mathrm{~m}$ for the strong and weak SBL, respectively. We must thus assume that even finer grid spacings may yield different results for the strong SBL, such as that investigated in the present intercomparison.

\subsection{Domain Size}

The sensitivity test to the size of the domain performed either for experiment 2 with the PALM model or for experiment 3 with the Meso-NH model shows very little change (not shown) and indicates that the domains chosen for the experiments are large enough. This is expected as the size of eddies is smaller than the scale of the boundary-layer height. During the convective period, the boundary-layer height reaches a maximum of $300 \mathrm{~m}$, and hence the $1000 \mathrm{~m}$-wide domain corresponds to three times this value. During the stable period, the boundary-layer height is less than $50 \mathrm{~m}$ and a $250 \mathrm{~m}$-wide domain corresponds to five times the size of the largest eddies, implying that a $500 \mathrm{~m}$-wide domain is sufficiently large. This is consistent with the results of Sullivan et al. (2016) for a set-up similar to the GABLS1 intercomparison. 
(a)

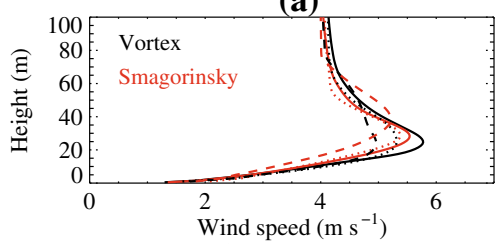

(c)
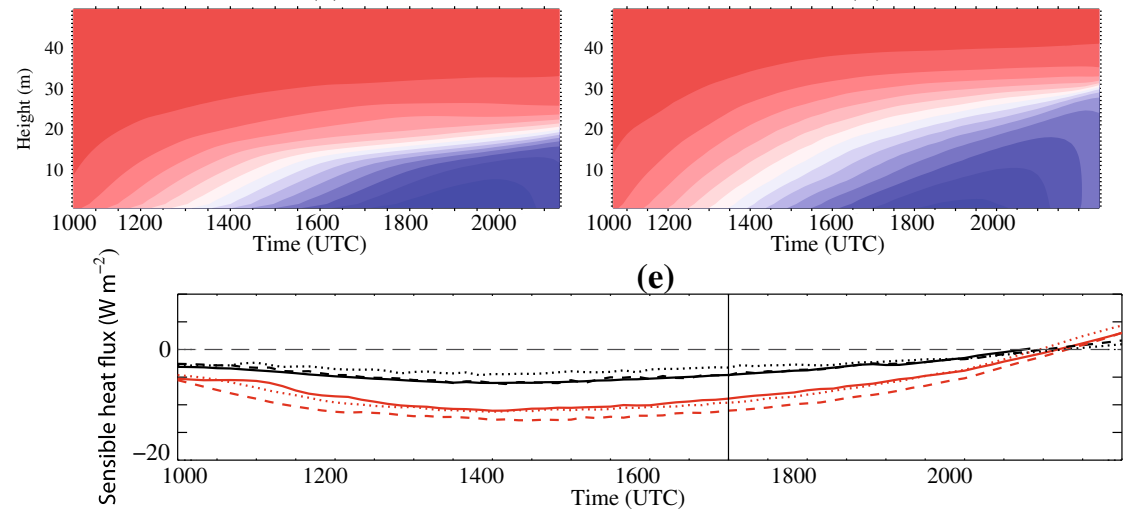

(b)

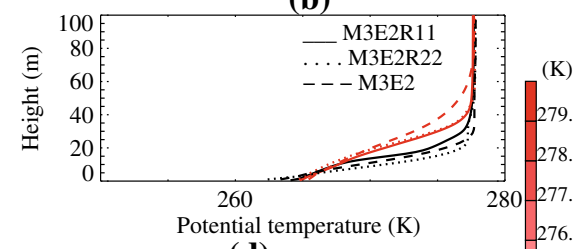

(d)
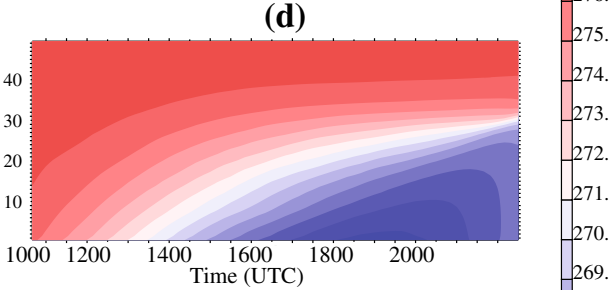

774.

Fig. 13 Vertical profiles at 1700 UTC of (a) wind speed and (b) potential temperature for the UConn model for two different SGS parametrizations and three different resolutions for experiment 2. Evolution of the vertical structure of mean potential temperature for both runs at $1 \mathrm{~m}$ resolution (c) with the buoyancyadjusted stretched-vortex parametrization (in black for the other panels) and (d) with the Smagorinsky parametrization (in red in the other panels) and (e) time series of the surface sensible heat flux for all runs

\subsection{Roughness Length}

The simulated turbulence close to the surface depends on the prescribed roughness length (Zilitinkevich et al. 2006). Miller and Stoll (2013) analyzed how the results of the GABLS1 intercomparison depend on the momentum and thermal roughness lengths showing a decrease of surface friction velocity, boundary-layer height and Obukhov length with lower roughness lengths. Here, we have tested how the results for this more stable case depend on prescribed values of roughness length. Five models were run with the two sets of roughness lengths, namely $10^{-2} \mathrm{~m}$ for momentum and $10^{-3} \mathrm{~m}$ for temperature for experiment 1 and $10^{-3} \mathrm{~m}$ for momentum and $10^{-4} \mathrm{~m}$ for temperature for experiment 2. As expected, weaker turbulence and a shallower boundary layer are simulated for the low-roughness simulations and the sensitivity is particularly high during the day (Fig. 3 and Table 3). Less sensitivity is seen during stable conditions. Indeed, during this later period, there is a competition between the decrease in shear production associated with the decrease of momentum roughness length and the decrease in buoyancy destruction associated with the decrease of the thermal roughness length. However, a second test performed with the MesoNH model for stable conditions with $z_{0 m}=10^{-3} \mathrm{~m}$ and the thermal roughness length of $10^{-3} \mathrm{~m}$ or $10^{-4} \mathrm{~m}$, reveals very little sensitivity to this change (not shown). 


\subsection{Subgrid Turbulence Parametrization}

The UConn model performed simulations using two different SGS parametrizations as detailed in Table 1. The reference parametrization is the buoyancy-adjusted stretched-vortex model (Chung and Matheou 2014), a structural turbulence closure where the SGS flow is composed of a collection of vortical structures, which are asymptotic exact solutions of the equations of motion. The additional simulations use the classical SGS parametrization of Smagorinsky (1963) and Lilly $(1962,1966)$. The turbulence closure constant of Cs = 0.2 and a turbulent Prandtl number $P r=0.33$ are used based on Matheou (2016). A comparison of the performance of the two closures for the GABLS1 intercomparison is presented in Matheou and Chung (2014). Further sensitivity aspects of the Smagorinsky parametrization for the GABLS1 intercomparison are discussed in Matheou (2016). There is very little difference between the two runs in convective conditions but a large sensitivity is revealed in stable conditions, as shown in Fig. 13 for the three resolutions $(5 \mathrm{~m}, 2 \mathrm{~m}, 1 \mathrm{~m})$. The Smagorinsky parametrization produces a deeper and less stratified SBL, as well as larger negative sensible heat fluxes. Analysis of the distribution of the anomalies of potential temperature indicates that the distribution from the simulation with the Smagorinsky parametrization is slightly narrower than the one from the observations, while the distribution of the simulation with the vortex model is slightly broader at $7 \mathrm{~m}$ above ground level. The largest difference between the two simulations is shown at $14 \mathrm{~m}$ above ground level, where no observation is available. Although further exploration of the difference between the Smagorinsky and the bouyancy-adjusted stretched-vortex parametrizations is beyond the scope here, the comparison highlights the strong sensitivity to the choice of the SGS parametrization.

\subsection{Surface Parametrization}

To assess the impact of the surface-flux parametrization, three models (MesoNH, PALM and UConn) provide additional runs with a prescribed surface-flux formulation based on MOST and derived from Eqs. 1 and 2 with $\beta_{m}=4.8$ and $\beta_{h}=7.8$. The results with the prescribed parametrization are similar to the original formulation, thus confirming that, (i) small variations in the MOST empirical fitting coefficients, and (ii) the implementation of the parametrization do not have a significant impact on the present results. Indeed, the surface Richardson number suggests weak stability where the different stability functions do not significantly diverge.

\section{Conclusion}

We have summarized the results of the fourth GABLS intercomparison for LES models focusing in strong SBL, which is challenging when simultaneously reproducing the convective boundary layer encountered even in extreme polar conditions in summer. Indeed, it is only recently that the high resolution needed for such simulations has become affordable. We investigated an idealized SBL although the set-up is inspired by observations. However, it was simplified compared with real observations with no subsidence, no contribution of radiation, no moisture and no time variation of the large-scale forcing, and thus did not expect agreement between the LES experiments and in situ observations. 
We demonstrated that the simulation of very stable conditions requires high spatial resolution: the spread of variables averaged over the horizontal domain is strongly reduced when increasing the horizontal and vertical resolutions from $5 \mathrm{~m}$ and $2 \mathrm{~m}$ to $1 \mathrm{~m}$ and $1 \mathrm{~m}$, respectively. As in previously published studies, in the majority of the models, the thinner SBL with a strong inversion is reproduced when using higher resolution. We showed that the grid length of at least $1 \mathrm{~m}$ is necessary to reproduce such cases. Indeed, a relative convergence of the mean profiles simulated by the different models is observed at such a resolution, suggesting the maturity of the LES approach in tackling extremely stable situations. However, even at this resolution, the models diverge for some quantities, such as the distribution of horizontal anomalies or second-order moments. For some of the models, sensitivity tests were performed to, (i) the resolution (horizontal and vertical); (ii) the size of the domain; (iii) the SGS parametrization; (iv) the thermodynamic profile used for initialization; and (v) the formulation used to compute surface fluxes. The results show no sensitivity to the size of the domain or the thermodynamical profile used for initialization, suggesting that the set-up has been well-defined. In addition, little sensitivity to the formulation used to compute surface fluxes is revealed. However, a strong sensitivity to the horizontal and vertical resolution, as well as to the choice of the SGS parametrization, is highlighted, suggesting that, at such high stability, the accuracy and skill of current LES models are significantly challenged. This also suggests that more work is needed on the dependence of the LES results on the choice of subgrid-turbulence parametrization and on the optimized approach in such highly stable conditions. This study highlights the fact that, while the LES approach should not be taken as an absolute reference in such stable conditions, it still provides an interesting guideline for the development of parametrizations.

Here, a simplified set-up has been used for the simulations, such as neglecting subsidence and radiation, and further studies are needed to document the different interplay between turbulence, radiation and eventually subsidence from observations and whether or not this partitioning is correctly reproduced by the LES approach, in line with Edwards (2009), Edwards et al. (2014), van der Linden et al. (2019) for instance. Preliminary tests from a more realistic case suggest that a similar turbulent behaviour is obtained with or without radiation if the water vapour content is set to zero, but this may hide some compensating errors and different thermodynamical equilibria. For future intercomparisons focusing on turbulence in the strong SBL, we recommend using a common simplified surface scheme and radiation scheme for all the models in order to allow interactions between these processes without bringing in additional sources of variability by new parametrizations.

Acknowledgements The first author would like to acknowledge E Coppa and B Alaoui who worked on a small internship on the first analysis of the intercomparison of the experiment 3 runs. The authors are also grateful to P LeMoigne, O Traullé, F Favot and W Maurel for their help in preparation of the GABLS4 intercomparaison and thanks B Holtslag for its promotion, and B. Holtslag and B Van de Wiel for the numerous and constructive discussions.

\section{Appendix 1: Initial Conditions}

Initial conditions and forcing for experiments 1, 2 and 3 of the GABLS4 intercomparison are provided in Table 5 . 
Table 5 Description of the initial profiles and forcing for the runs initialized at 0000 UTC or at 1000 UTC as well as the time series of the prescribed surface temperature

\begin{tabular}{|c|c|c|c|c|c|c|c|}
\hline \multirow[t]{2}{*}{ Height (m) } & \multicolumn{4}{|c|}{ Initial profiles } & & \multicolumn{2}{|l|}{ Forcings } \\
\hline & $\theta(\mathrm{K})$ & \multicolumn{2}{|l|}{$U\left(\mathrm{~m} \mathrm{~s}^{-1}\right)$} & \multicolumn{2}{|l|}{$V\left(\mathrm{~m} \mathrm{~s}^{-1}\right)$} & $U_{g}\left(\mathrm{~m} \mathrm{~s}^{-1}\right)$ & $V_{g}\left(\mathrm{~m} \mathrm{~s}^{-1}\right)$ \\
\hline \multicolumn{8}{|c|}{ Forcing for the runs initialized at 0000 UTC } \\
\hline 0 & 271.3 & 0 & & 0 & & 0 & 0 \\
\hline 2.5 & 271.3 & 1.25 & & 4.5 & & 1.25 & 4.5 \\
\hline 7.5 & 271.1 & 1.25 & & 4.5 & & 1.25 & 4.5 \\
\hline 43.4 & 275.4 & 1.25 & & 4.5 & & 1.25 & 4.5 \\
\hline 296.2 & 278.4 & 1.25 & & 4.5 & & 1.25 & 4.5 \\
\hline 655. & 281.1 & 1.25 & & 4.5 & & 1.25 & 4.5 \\
\hline 702. & 281.5 & 1.27 & & 4.7 & & 1.27 & 4.7 \\
\hline 1043. & 284.2 & 2.13 & & 5.35 & & 2.13 & 5.35 \\
\hline \multicolumn{8}{|c|}{ Forcing for the runs initialized at 1000 UTC } \\
\hline 0 & 276.58 & 0 & & 0 & & 0 & 0 \\
\hline 2.5 & 276.58 & 1.42 & & 1.62 & & 1.25 & 4.5 \\
\hline 12.7 & 277.15 & 2.07 & & 2.81 & & 1.25 & 4.5 \\
\hline 17.9 & 277.34 & 2.22 & & 3.32 & & 1.25 & 4.5 \\
\hline 33.4 & 277.63 & 2.34 & & 4.32 & & 1.25 & 4.5 \\
\hline 49.6 & 277.69 & 2.31 & & 4.64 & & 1.25 & 4.5 \\
\hline 61.2 & 277.7 & 2.30 & & 4.71 & & 1.25 & 4.5 \\
\hline 120.2 & 277.71 & 2.27 & & 4.84 & & 1.25 & 4.5 \\
\hline 150. & 277.71 & 2.25 & & 4.87 & & 1.25 & 4.5 \\
\hline Time & 01 & 04 & 05 & 06 & 07 & 08 & 10 \\
\hline
\end{tabular}

Prescribed surface temperature

\begin{tabular}{lllllllllllllll}
$\mathrm{T}(\mathrm{K})$ & 241.5 & 243.29 & 245 & 246.35 & 247.07 & 247.44 & 247.43 & 247.05 & 246.4 & 245.1 & 243.31 & 241.21 \\
\hline Time & 12 & 13 & 14 & 15 & 16 & 17 & 18 & 19 & 20 & 21 & 22 & 23 & 24 \\
\hline
\end{tabular}

Prescribed surface temperature

$\mathrm{T}(\mathrm{K}) \quad 238.86236 .67234 .43231 .92231 .24231 .15231 .71232 .79234 .58236 .5238 .82241 .25243 .23$

\section{References}

Basu S, Porte-Agel F (2006) Large-eddy simulation of stably stratified atmospheric boundary layer turbulence: a scale-dependent dynamic modeling approach. J Atmos Sci 63:2074-2091

Bazile E, Couvreux F, Le Moigne P, Genthon C, Holtslag AAM, Svensson G (2014) GABLS4: an intercomparison case to study the stable boundary layer over the Antarctic plateau. Global Ener Water Cycle Exper News 24(4):4

Beare RJ, Macvean MK, Holtslag AAM, Cuxart J, Golaz J-C, Jimenez MA, Khairoutdinov M, Kosovic M, Lewellen D, Lund TS, Lundquist JK, Mccabe A, Moene AF, Noh Y, Raasch S, Sullivan P (2006) An intercomparison of large-eddy simulations of the stable boundary layer. Boundary-Layer Meteorol 118:247-272

Bosveld FC, Baas P, Steeneveld G-J, Holtslag AAM, Wangevine WM, Bazile E, de Bruijn EIF, Deacu D, Edwards JM, Ek M, Larson VE, Pleim JE, Raschendorfer M, Svensson G (2014a) The third GABLS intercomparison case for evaluation studies of boundary-layer models. Part B: results and process understanding. Boundary-Layer Meteorol 152:157-187 
Bosveld FC, Baas P, van Meijgaard E, de Bruijn EIF, Steeneveld G-J, Holtslag AAM (2014b) The third GABLS intercomparison case for evaluation studies of boundary-layer models. Part A: case selection and set-up. Boundary-Layer Meteorol 152:133-156

Bou-Zeid E, Meneveau C, Parlange M (2005) A scale-dependent Lagrangian dynamic model for large eddy simulation of complex turbulent flows. Phys Fluids 17:025105

Bou-Zeid E, Higgins C, Huwald H, Parlange MB, Meneveau C (2010) Field study of the dynamics and modelling of subgrid scale turbulence in a stable atmospheric surface layer over a glacier. J Fluid Mech 665:480-515

Brown N, Weiland M, Hill A, Shipway B, Maynard C, Allen T, Rezny M (2015) A highly scalable met office NERC cloud model. In: Proceedings of the 3rd international conference on exascale applications and software. Edinburgh, UK, April 2015

Casasanta G, Pietroni I, Petenko I, Argentini S (2014) Observed and modelled convective mixing-layer height at dome C, Antarctica. Boundary-Layer Meteorol 151:597-608

Cheng A, Xu K-M (2011) Preliminary results from a multiscale modeling framework with a third-order turbulence closure in its cloud-resolving model component. J Geophys Res 116:D14101

Chung D, Matheou G (2012) Direct numerical simulation of stationary homogeneous stratified sheared turbulence. J Fluid Mech 696:434-467

Chung D, Matheou G (2014) Large-Eddy simulation of stratified turbulence. Part I: a vortex-based subgridscale model. J Atmos Sci 71:1863-1879

Cuxart J, Holtslag AAM, Beare RJ, Bazile E, Beljaars A, Cheng A, Canangla L, Ek M, Freedman F, Hamdi R, Kerstein A, Kitagawa H, Lenderink G, Lewellen D, Mailhot J, Mauritsen T, Perov V, Schayes G, Steeneveld G-J, Svensson G, Taylor P, Weng W, Wunsch S, Xu K-M (2006) Single-column model intercomparison for a stably stratified atmospheric boundary layer. Boundary-Layer Meteorol 118:273-303

Deardorff JW (1974) Three-dimensional numerical study of the height and mean structure or a heated planetary boundary layer. Boundary-Layer Meteorol 7:81-106

Deardorff JW (1980) Stratocumulus-capped mixed layers derived from a three-dimensional model. Boundary-Layer Meteorol 18:495-527

Edwards JM (2009) Radiative processes in the stable boundary layer: part II. The development of the nocturnal boundary layer. Boundary-Layer Meteorol 131:127-146

Edwards JM, Basu S, Bosveld FC, Holtslag AAM (2014) The impact of radiation on the GABLS3 largeeddy simulation through the night and during the morning transition. Boundary-Layer Meteorol 152:189-211

Fuka V (2015) PoisFFT - a free parallel fast Poisson solver. Appl Math Comput 267:356-364

Fuka V, Brechler J (2011) Large Eddy simulation of the stable boundary Layer. In: Fort J, Furst J, Halama J, Herbin R, Hubert F (eds) Finite volumes for complex applications Vi: problems \& perspectives, vol $1, \mathrm{pp} 485-493$

Genthon C, Six D, Gallee H, Grigioni P, Pellegrini A (2013) Two years of atmospheric boundary layer observations on a 45-m tower at Dome C on the Antarctic plateau. J Geophys Res Atmos 118:3218-3232

Genthon C, Piard L, Vignon E, Madeleine J-B, Casado M, Gallée H (2017) Atmospheric moisture supersaturation in the near-surface atmosphere at Dome C, Antarctic Plateau. Atmos Chem Phys 17:1-14

Ha K-J, Hyun Y-K, Oh H-M, Kim K-E, Mahrt L (2007) Evaluation of boundary layer similarity theory for stable conditions in CASES-99. Mon Weather Rev 135(10):3474-3483

Heus T, van Heerwaarden CC, Jonker HJJ, Siebesma AP, Axelsen S, van den Dries K, Geoffroy O, Moene AF, Pino D, de Roode SR, Ja Vila-Guerau (2010) Formulation of the Dutch atmospheric large-eddy simulation (DALES) and overview of its applications. Geosci Model Dev 3:415-444

Högström U (1988) Non-dimensional wind and temperature profiles in the atmospheric surface layer: a reevaluation. Boundary-Layer Meteorol 42:55-78

Holtslag AAM, Svensson G, Baas P, Basu S, Beare B, Beljaars ACM, Bosveld FC, Cuxart J, Lindvall J, Steeneveld GJ, Tjernstrom M, Van de Wiel BJH (2013) Stable atmospheric boundary layers and diurnal cycles challenges for weather and climate models. Bull Am Meteorol Soc 94:1691-1706

Hourdin F, Grandpeix J-Y, Rio C, Bony S, Jam A, Chéruy F, Rochetin N, Fairhead L, Idelkadi A, Musat I, Dufresne J-L, Lahellec A, Lefebvre M-P, Roehrig R (2013) LMDZ5B: the atmospheric component of the IPSL climate model with revisited parameterizations for clouds and convection. Clim Dyn 40:2193-2222

Huang J, Bou-Zeid E (2013) Turbulence and vertical fluxes in the stable atmospheric boundary layer. Part I: a large-eddy simulation study. J Atmos Sci 70:1513-1527

Khairoutdinov MF, Randall DA (2003) Cloud resolving modeling of the ARM summer 1997 IOP: model formulation, results, uncertainties, and sensitivities. J Atmos Sci 60:607-625 
King JC, Connolley WM, Derbyshire SH (2001) Sensitivity of modelled Antarctic climate to surface and boundary-layer flux parametrizations. Q J R Meteorol Soc 127:779-794

King JC, Argentini SA, Anderson PS (2006) Contrasts between the summertime surface energy balance and boundary layer structure at Dome $\mathrm{C}$ and Halley stations. Antarctica, J Geophys Res Atmos, p 111

Lac C, Chaboureau P, Masson V, Pinty P, Tulet P, Escobar J, Leriche M, Barthe C, Aouizerats B, Augros C, Aumond P, Auguste F, Bechtold P, Berther S, Bielli S, Bosseur F, Caumont O, Cohard JM, Colin J, Couvreux F, Cuxart J, Delautier G, Dauhut T, Ducrocq V, Filippi JB, Gazen D, Geoffroy O, Gheusi F, Honnert R, Lafore JP, Lebeaupin Brossier C, Libois Q, Lunet T, Mari C, Maric T, Mascart P, Mogé M, Molinié G, Nuissier O, Pantillon F, Peyrillé P, Pergaud J, Perraud E, Pianezze J, Redelsperger JL, Ricard D, Richard E, Riette S, Rodier Q, Seyfried Schoetter R, Stein J, Suhre K, Taufour M, Thouron O, Turner S, Verrelle A, Vié B, Visentin F, Vionnet V, Wautelet P (2018) Overview of the Meso-NH model version 5.4 and its applications. Geosci Model Dev 298:1-66

Lilly DK (1962) On the numerical simulation of buoyant convection. Tellus 14:148-172

Lilly D K (1966) On the application of the eddy viscosity concept. The inertial sub-range of turbulence, NCAR manuscript 123. National Center for Atmospheric Research: Boulder, CO

Mahrt L (1999) Stratified atmospheric boundary layers. Boundary-Layer Meteorol 90:375-396

Mahrt L (2008) Bulk formulation of surface fluxes extended to weak-wind stable conditions. Q J R Meteorol Soc 134:1-10

Mahrt L (2010) Variability and maintenance of turbulence in the very stable boundary layer. BoundaryLayer Meteorol 135:1-18

Mahrt L (2014) Stably stratified atmospheric boundary layers. Annu Rev Fluid Mech 46:23-45

Mahrt L, Larsen S (1990) Relation of slope winds to the ambient flow over gentle terrain. BoundaryLayer Meteorol 53:93-102

Maronga B, Griyschka M, Heinze R, Hoffmann F, Kanani-Suhring F, Keck M, Ketelsen K, Letzel MO, Suhring M, Raasch S (2015) The parallelized large-eddy simulation model (PALM) version 4.0 for atmospheric and oceanic flows: model formulation, recent developments, and future perspectives. Geosci Model Dev 8:2515-2551

Maronga, B, C Knigge, S Raasch (2020a) An improved surface boundary condition for large eddy simulations based on Monin-Obukhov similarity theory: evaluation and consequences for grid convergence in neutral and stable conditions. In press Boundary-Layer Meteorol

Maronga B, Banzhaf S, Burmeister C, Esch T, Forkel R, Fröhlich D, Fuka V, Gehrke KG, Geletič J, Giersch S, Gronemeier T, Groß G, Heldens W, Hellsten A, Hoffmann F, Inagaki A, Kadasch E, Kanani-Sühring F, Ketelsen K, Khan BA, Knigge C, Knoop H, Krč P, Kurppa M, Maamari H, Matzarakis A, Mauder M, Pallasch M, Pavlik D, Pfafferott J, Resler J, Rissmann S, Russo E, Salim M, Schrempf M, Schwenkel J, Seckmeyer G, Schubert S, Sühring M, von Tils R, Vollmer L, Ward S, Witha B, Wurps H, Zeidler J, Raasch S (2020) Overview of the PALM model system 6.0. Geosci Model Dev 13:1335-1372. https://doi.org/10.5194/gmd-2019-103

Matheou G (2016) Numerical discretization and subgrid-scale model effects on large-eddy simulations of a stable boundary layer. Q J R Meteorol Soc 142:3050-3062

Matheou G, Chung D (2012) Direct numerical simulation of stratified turbulence. Phys Fluids 24:091106

Matheou G, Chung D (2014) Large-eddy simulation of stratified turbulence. Part II: application of the stretched-vortex model to the atmospheric boundary layer. J Atmos Sci 71:45-66

Miller NE, Stoll R (2013) Surface heterogeneity effects on regional-scale fluxes in the stable boundary layer: aerodynamic roughness length transition. Boundary-Layer Meteorol 149:277-301

Morinishi Y, Lund TS, Vasilyev OV, Moin P (1998) Fully conservative higher order finite difference schemes for incompressible flow. J Comput Phys 143:90-124

Noilhan J, Planton S (1989) A simple parameterization of land surface processes for meteorological models. Mon Weather Rev 117:536-549

Rabier F, Bouchard A, Brun E, Doerenbecher A, Guedj S, Guidard V, Karbou F, Peuch V-H, El Amraoui L, Puech D, Genthon C, Picard G, Town M, Hertzog A, Vial F, Cocquerez P, Cohn SA, Hock T, Fox J, Cole H, Parsons D, Powers J, Romberg K, VanAndel J, Deshler T, Mercer J, Haase JS, Avallone L, Kalnajs L, Mechoso CR, Tangborn A, Pellegrini A, Frenot Y, Thépaut J-N, McNally A, Basamo G, Steinle P (2010) The concordiasi project. Antarctica Bull Am Meteorol Soc 91:69-86

Randall D, Khairoutdinov M, Arakawa A, Grabowski W (2003) Breaking the cloud parameterization deadlock. Bull Am Meteorol Soc 84:1547-1564

Ricaud P, Genthon C, Durand P, Attié J, Carminati F, Canut G, Vanacker J, Moggio L, Courcoux Y, Pellegrini A, Rose T (2012) Summer to winter diurnal variabilities of temperature and water vapour in the lowermost troposphere as observed by HAMSTRAD over Dome C, Antarctica. Boundary-Layer Meteorol 143:227-259 
Sandu I, Beljaars A, Bechtold P, Mauritsen T, Balsamo G (2013) Why is it so difficult to represent stably stratified conditions in numerical weather prediction (NWP) models? J Adv Model Earth Syst 5:117-133

Smagorinsky J (1963) General circulation experiments with the primitive equations I: the basic experiment. Mon Weather Rev 91:99-164

Sullivan PP, Weil JC, Patton EG, Jonker HJJ, Mironov DV (2016) Turbulent Winds And Temperature Fronts In Large-Eddy Simulations Of The Stable Atmospheric Boundary Layer. J Atmos Sci 73:1815-1840

Sun J, Mahrt L, Banta RM, Pichugina YL (2012) Turbulence regimes and turbulence intermittency in the stable boundary layer during CASES-99. J Atmos Sci 69:338-351

Svensson G, Holtslag AAM, Kumar V, Mauritsen T, Steenveld G-J, Angevine WM, Bazile E, Beljaars A, de Bruijn EIF, Cheng A, Conangla L, Cuxart J, Ek M, Falk MJ, Freedman F, Kitagawa H, Larson VE, Lock A, Mailhot J, Masson V, Park S, Pleim J, Soderberg S, Weng W, Zampieri M (2011) Evaluation of the diurnal cycle in the atmospheric boundary layer over land as represented by a variety of singlecolumn models: the second GABLS experiment. Boundary-Layer Meteorol 140:177-206

Van de Wiel BJH, Moene AF, Jonker HJJ, Baas P, Basu S, Donda JMM, Sun J, Holtslag AAM (2012) The minimum wind speed for sustainable turbulence in the nocturnal boundary layer. J Atmos Sci 69:3116-3127

van der Linden SA, Edwards JM, van Heerwaarden CC, Vignon E, Genthon C, Petenko I, Baas P, Jonker HJJ, van de Wiel BJH (2019) Large-Eddy simulations of the steady wintertime antarctic boundary layer. Boundary-Layer Meteorol 173:165-192

van Heerwaarden CC, van Stratum BJH, Heus T, Gibbs JA, Fedorovich E, Mellado JP (2017) MicroHH 1.0: a computational fluid dynamics code for direct numerical simulation and large-eddy simulation of atmospheric boundary layer flows. Geosci Model Dev 10:3145-3165

Van Stratum BJ, Stevens B (2015) The influence of misrepresenting the nocturnal boundary layer on idealized daytime convection in large-eddy simulation. J Adv Model Earth Syst 7:423-436

Vignon E, van de Wiel BJH, van Hooijdonk IGS, Genthon C, van der Linden SJA, van Hooft A, Baas P, Maurel W, Traullé O, Casasanta G (2017a) Stable boundary-layer regimes at Dome C, Antarctica: observation and analysis. Q J R Meteorol Soc 143:1241-1253

Vignon E, Genthon C, Barral H, Amory C, Picard G, Gallee H, Casasanta G, Argentini S (2017b) Momentum- and heat-flux parametrization at Dome C, Antarctica: a sensitivity study. Boundary-Layer Meteorol 162:341-367

Vignon E, Hourdin F, Genthon C, Gallée H, Bazile E, Lefebvre M-P, Madeleine J-B, Van de Wiel BJH (2017c) Antarctic boundary layer parametrization in a general circulation model: 1-D simulations facing summer observations at Dome C. J Geophys Res Atmos 122:6818-6843

Walesby KT, Beare RJ (2016) Parametrizing the Antarctic stable boundary layer: synthesizing models and observations. Q J R Meteorol Soc 142:2373-2385

Wicker LJ, Skamarock WC (2002) Time-splitting methods for elastic models using forward time schemes. Mon Weather Rev 130:2088-2097

Wilson DK (2001) An alternative function for the wind and temperature gradients in unstable surface layers. Boundary-Layer Meteorol 99:151-158

Zilitinkevich SS, Hunt JCR, Esau IN, Grachev AA, Lalas DP, Akylas E, Tombrou M, Fairall CW, Fernando HJS, Baklanov AA, Joffre SM (2006) The influence of large convective eddies on the surface-layer turbulence. Q J R Meteorol Soc 132:1423-1456

Publisher's Note Springer Nature remains neutral with regard to jurisdictional claims in published maps and institutional affiliations.

\section{Affiliations}

Fleur Couvreux ${ }^{1}$ (D) Eric Bazile $^{1} \cdot$ Quentin Rodier $^{1} \cdot$ Björn Maronga $^{2,3}$. Georgios Matheou ${ }^{4}$ Maria J. Chinita ${ }^{5,6}$. John Edwards ${ }^{7}$ Bart J. H. van Stratum ${ }^{8}$. Chiel C. van Heerwaarden ${ }^{8}$. Jing Huang ${ }^{9}$ (i) . Arnold F. Moene ${ }^{8} \cdot$ Anning Cheng $^{10}$. Vladimir Fuka ${ }^{12}$. Sukanta Basu ${ }^{11}$. Elie Bou-Zeid ${ }^{13}$. Guylaine Canut ${ }^{1}$. Etienne Vignon ${ }^{14,15}$

1 CNRM, Université de Toulouse Météo-France CNRS, 31057 Toulouse, France 
2 Institute of Meteorology and Climatology, Leibniz University Hannover, Hannover, Germany

3 Geophysical Institute, University of Bergen, Bergen, Norway

4 Department of Mechanical Engineering, University of Connecticut, Storrs, USA

5 Joint Institute for Regional Earth System Science and Engineering, University of California and Jet Propulsion Laboratory, California Institute of Technology, Pasadena, CA, USA

6 Faculdade de Ciencias, Instituto Dom Luiz, Universidade de Lisboa, Lisbon, Portugal

7 Met Office, Exeter, UK

8 Wageningen University and Research, Wageningen, The Netherlands

9 Oceans and Atmosphere, CSIRO, Canberra, Australia

10 IMSG Inc./Environmental Modeling Center, National Centers for Environmental Protection, Center for Weather and Climate Prediction, College Park, USA

11 Delft University of Technology, Delft, The Netherlands

12 Department of Atmospheric Physics, Faculty of Mathematics and Physics, Charles University, Prague, Czech Republic

13 Department of Civil and Environmental Engineering, Princeton University, Princeton, USA

14 LTE, Ecole Polytechnique Fédérale de Lausanne, Lausanne, Switzerland

15 Institut des Géosciences de l'Environnement CNRS, Université Grenoble Alpes, Grenoble, France 